\title{
Fibril growth and seeding capacity play key roles in a-synuclein-mediated apoptotic cell death
}

\author{
A-L Mahul-Mellier ${ }^{1,3}$, F Vercruysse $^{1,3}$, B Maco ${ }^{1}$, N Ait-Bouziad ${ }^{1}$, M De Roo ${ }^{2}$, D Muller ${ }^{2}$ and HA Lashuel ${ }^{\star, 1}$
}

The role of extracellular $\alpha$-synuclein ( $\alpha$-syn) in the initiation and the spreading of neurodegeneration in Parkinson's disease (PD) has been studied extensively over the past 10 years. However, the nature of the $\alpha$-syn toxic species and the molecular mechanisms by which they may contribute to neuronal cell loss remain controversial. In this study, we show that fully characterized recombinant monomeric, fibrillar or stabilized forms of oligomeric $\alpha$-syn do not trigger significant cell death when added individually to neuroblastoma cell lines. However, a mixture of preformed fibrils (PFFs) with monomeric $\alpha$-syn becomes toxic under conditions that promote their growth and amyloid formation. In hippocampal primary neurons and ex vivo hippocampal slice cultures, $\alpha$-syn PFFs are capable of inducing a moderate toxicity over time that is greatly exacerbated upon promoting fibril growth by addition of monomeric $\alpha$-syn. The causal relationship between $\alpha$-syn aggregation and cellular toxicity was further investigated by assessing the effect of inhibiting fibrillization on $\alpha$-syn-induced cell death. Remarkably, our data show that blocking fibril growth by treatment with known pharmacological inhibitor of $\alpha$-syn fibrillization (Tolcapone) or replacing monomeric $\alpha$-syn by monomeric $\beta$-synuclein in $\alpha$-syn mixture composition prevent $\alpha$-syn-induced toxicity in both neuroblastoma cell lines and hippocampal primary neurons. We demonstrate that exogenously added $\alpha$-syn fibrils bind to the plasma membrane and serve as nucleation sites for the formation of $\alpha$-syn fibrils and promote the accumulation and internalization of these aggregates that in turn activate both the extrinsic and intrinsic apoptotic cell death pathways in our cellular models. Our results support the hypothesis that ongoing aggregation and fibrillization of extracellular $\alpha$-syn play central roles in $\alpha$-syn extracellular toxicity, and suggest that inhibiting fibril growth and seeding capacity constitute a viable strategy for protecting against $\alpha$-syn-induced toxicity and slowing the progression of neurodegeneration in PD and other synucleinopathies.

Cell Death and Differentiation (2015) 22, 2107-2122; doi:10.1038/cdd.2015.79; published online 3 July 2015

The discovery of $a$-synuclein ( $a$-syn) as the main component of Lewy bodies (LBs) and the identification of gene duplication and missense mutations in the a-syn gene in some familial forms of Parkinson's disease (PD) have reinforced the central role of $a$-syn in the etiology of both sporadic and familial cases of PD. ${ }^{1}$ Nevertheless, the relationship between $a$-syn aggregation and neurodegeneration in PD remains elusive. ${ }^{2}$

A possible role for extracellular $a$-syn in the pathogenicity of PD emerged from the observation that newly grafted neurons in PD patients exhibit $a$-syn pathology similar to that of neighboring diseased cells. ${ }^{3,4}$ Despite the consensus that $a$-syn is mainly an intracellular protein, $a$-syn has been detected in the cerebrospinal fluid under both pathological and healthy conditions. ${ }^{5}$ In addition, in vivo rodent models and cellular studies have shown that monomers ${ }^{6}$ and aggregated forms $s^{6,7}$ of $a$-syn are secreted into the extracellular space via several mechanisms, ${ }^{7,8}$ including the nonclassical endoplasmic reticulum/Golgi-independent exocytosis ${ }^{8}$ or the exosomal route, ${ }^{9,10}$ and are then internalized by neighboring cells. ${ }^{7}$ This suggests that extracellular $a$-syn may play a critical role in the spreading of $a$-syn pathology throughout the brain and contributes to PD progression.

Additional evidence for a causal role of extracellular $a$-syn in PD come from in vivo studies and cell culture models: (1) intracranial injections of pathological forms of $a$-syn, isolated from LBs or old mice, as well as recombinant $a$-syn fibrils, were shown to nucleate further $a$-syn aggregation, pathology spreading and trigger neurodegeneration in vivo in wildtype (WT) or transgenic mice ${ }^{11-14}$ and rhesus monkeys; ${ }^{15}$ (2) recombinant extracellular $a$-syn aggregates are internalized in cultured cells and seed the aggregation of endogenous $a$-syn; ${ }^{12,16-18}$ and (3) extracellular $a$-syn activates microglia that initiates or enhances nigral neurodegeneration. ${ }^{19-21}$ Although the toxic effects of exogenous recombinant $a$-syn have been thoroughly investigated in different cellular models, ${ }^{7,17,18,22-25}$ the relative contribution of monomeric, oligomeric and fibrillar forms of $a$-syn to the overall toxicity remains controversial. Therefore, the identification of toxic $a$-syn species and the molecular mechanisms by which they contribute to neurodegeneration is required to better

\footnotetext{
${ }^{1}$ Laboratory of Molecular and Chemical Biology of Neurodegeneration, Brain Mind Institute, Ecole Polytechnique Fédérale de Lausanne, Lausanne 1015, Switzerland and 2Département des Neurosciences Fondamentales, Université de Genève, Faculté de Médecine, Centre Médical Universitaire, 1211 Genève 4, Switzerland

*Corresponding author: HA Lashuel, Laboratory of Molecular and Chemical Biology of Neurodegeneration, Brain Mind Institute, Ecole Polytechnique Fédérale de Lausanne, Lausanne 1015, Switzerland. Tel: +41 21693 0792; Fax: +41 21693 1780; E-mail: hilal.lashuel@epfl.ch

${ }^{3}$ These authors contributed equally to this work.

Abbreviations: PD, Parkinson's disease; $\alpha$-syn, $\alpha$-synuclein; $\alpha$-syn PFF, $\alpha$-synuclein preformed fibril; PI, propidium iodide; SG, Sytox green; TUNEL, terminal deoxynucleotidyl transferase-mediated dUTP-biotin nick end labeling; TEM, transmission electron microscopy; CLEM, correlative light and electron microscopy; DIV, day in vitro

Received 15.12.14; revised 30.4.15; accepted 06.5.15; Edited by M Freeman; published online 03.7.15
} 
understand how extracellular $a$-syn contributes to PD pathogenesis and to develop novel strategies for the diagnosis and treatment of PD and other synucleinopathies. In our study we explored the relationship between neurotoxicity and the aggregation state or amyloid formation propensity of $a$-syn in various cellular models.

\section{Results}

Preparation and characterization of $\boldsymbol{a}$-syn species. We first developed reproducible protocols for generating different $a$-syn species and characterizing their biophysical and structural properties using an array of biophysical methods. ${ }^{26,27}$ Recombinant monomeric WT human $a$-syn was produced as previously described, ${ }^{28}$ and its purity was confirmed by SDS-PAGE, mass spectrometry and reversephase ultra-performance liquid chromatography (RP-UPLC) analyses (Figures 1a-c). Preformed $a$-syn fibrils (PFFs) were then generated from monomeric $a$-syn as previously described, ${ }^{28}$ and subjected to sonication to generate a preparation of homogenous PFFs with an average length of 50-150 nm. Fibril formation was confirmed by the Thioflavin T (ThT) binding assay and transmission electron microscopy (TEM) (Figures $1 \mathrm{~d}-\mathrm{g}$ ). Finally, $a$-syn oligomers were produced by coincubation of monomeric $a$-syn with excess dopamine. ${ }^{29-31}$ Under these conditions, $\sim 50 \%$ of monomeric a-syn was converted to oligomers after 4 days, as assessed by size exclusion chromatography (SEC) (Figure 1h). The purity, heterogeneity and amyloidogenic properties of $a$-syn oligomers were assessed by SEC, SDS-PAGE electrophoresis, TEM and ThT binding assay (Figures $1 \mathrm{~h}-\mathrm{k}$ ).

A mixture of a-syn monomers and fibrils but not individual $a$-syn species is toxic to neuroblastoma cell lines. We first compared the toxic properties of the purified $a$-syn species in human dopaminergic neuroblastoma cell lines (M17 and SH-S5Y5 cells). Using the uptake of the vital dye propidium iodide (PI) as a marker for membrane disruption and toxicity, in combination with flow cytometry quantification, we observed that neither a-syn monomers (Figure 2a and Supplementary Figure S1A), $a$-syn PFFs (Figure $2 \mathrm{~b}$ and Supplementary Figure S1B) nor $a$-syn oligomers induced cell death when added extracellularly to the cells (Figure $2 \mathrm{c}$ ).

Although several studies have shown that different aggregated forms of $a$-syn exhibit toxicity in various cellular ${ }^{17,20,23,32}$ and in vivo models, ${ }^{12,32}$ increasing evidence from our group $^{27,33}$ and others ${ }^{34}$ suggest that amyloid toxicity could be linked to the process of amyloid formation rather than to specific aggregated forms of amyloidogenic proteins. To determine whether this applies to $a$-syn-induced toxicity, we assessed the effect of inducing fibril growth by the addition of $a$-syn PFFs (10\%) to monomeric $a$-syn solutions.

Unlike $a$-syn monomers or PFFs added alone, addition of a mixture of both species induced cell death in a concentrationand time-dependent manner (Figure 2d and Supplementary Figure S1C). Interestingly, we observed significant toxicity $(\sim 15-20 \%)$ for $a$-syn mixture even at low protein concentrations (Figure 2d and Supplementary Figure S1C). We next showed that ThT fluorescence increased over time only in the media of M17 cells treated with $a$-syn mixture, supporting a correlation between ongoing fibrillization and cell death (Supplementary Figure S2). Increasing the proportion of $a$-syn PFFs to $20 \%$ did not exacerbate $a$-syn toxicity (Supplementary Figure S3), indicating that the presence of $10 \%$ of fibrillar material is sufficient to initiate $a$-syn fibrillization and trigger cell death. Interestingly, addition of a mixture of $a$-syn monomers and dopamine-induced oligomers did not result in any significant cellular toxicity (Figure $2 e$ ), consistent with previous reports. ${ }^{29,30,35}$ We then investigated which mechanism of cell death was induced by $a$-syn fibrillization. After 4 days of treatment, $\sim 50 \%$ of the cells showed caspase 3 activation and DNA fragmentation (Figures $2 f$ and $g$ and Supplementary Figures S1D and E), indicating that $a$-syn mixture induced apoptosis in neuroblastoma cell lines.

\section{A mixture of $\boldsymbol{\alpha}$-syn monomers and fibrils exacerbates cell} death in primary hippocampal neurons and in ex vivo hippocampal slice cultures. To validate our findings, we then assessed the toxicity of the various $a$-syn species in a co-culture of primary hippocampal neurons and glial cells (Figure 3). As observed in the cell lines, the addition of monomeric or oligomeric $a$-syn alone did not induce any significant cell death over time (Figures 3a and c). However, although no significant toxicity was observed upon $a$-syn PFF treatment at 3 days, $a$-syn PFF started to be toxic after 6 days of treatment (Figure $3 b$ ). Moreover, the addition of a mixture of PFFs and monomeric species greatly exacerbated $a$-syn toxicity in a concentration- and time-dependent manner (Figure 3d). In contrast, addition of a mixture of $a$-syn monomers and dopamine-induced oligomers did not result in any significant cellular toxicity (Figure $3 e$ ).

The $a$-syn PFFs alone or a mixture of PFFs and monomers induced apoptosis in primary culture (Figures $3 f$ and $\mathrm{g}$ ), with most of cell death observed for $a$-syn mixture. Importantly, under these conditions, the neuronal population, positively stained for a specific neuronal marker (NeuN), was severely affected as shown after TUNEL (terminal deoxynucleotidyl transferase-mediated dUTP-biotin nick end labeling) counting (Figure $3 \mathrm{~g}$ ) and by the reduction in NeuN intensity (Supplementary Figure S4).

We then assessed the response of organotypic hippocampal slice cultures to the different extracellular $a$-syn species, as these maintain some intrinsic connectivity and spatial organization as in the brain and therefore represent a more physiologically relevant neuronal model (Figure 4a). a-Syn monomers were not toxic in hippocampal slice cultures at concentrations up to $10 \mu \mathrm{M}$ (Figures $4 \mathrm{~b}$ and $\mathrm{c}$ ), whereas $a$-syn PFFs induced significant toxicity (Figures $4 b$ and $d$ ) that was further exacerbated upon mixing with monomers (Figures $4 \mathrm{~b}$ and e).

Taken together, our results suggest that the increased toxicity observed with the mixture containing $a$-syn PFFs and monomers might be linked to the ability of the fibrils to grow by incorporation of monomers, and to seed further aggregation.

Inhibiting fibril growth and seeding capacity decreases $\boldsymbol{a}$-syn-induced toxicity. To test this hypothesis, we evaluated the effect of inhibiting fibrillar growth and amyloid fibril formation in $a$-syn mixture using Tolcapone, a small-molecule 
a

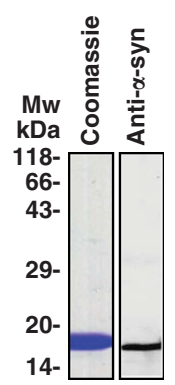

b

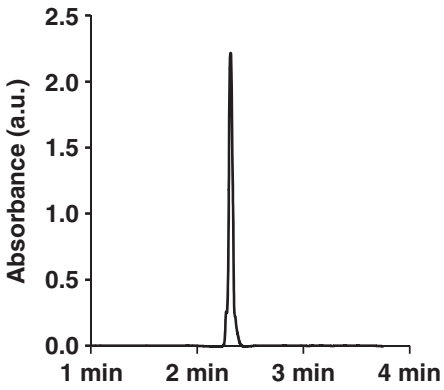

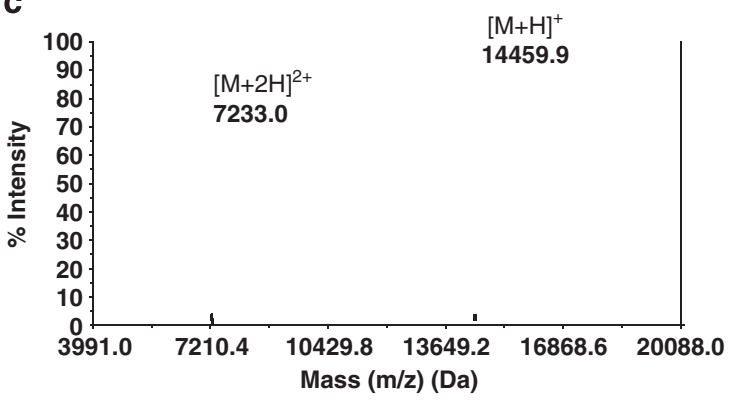

d
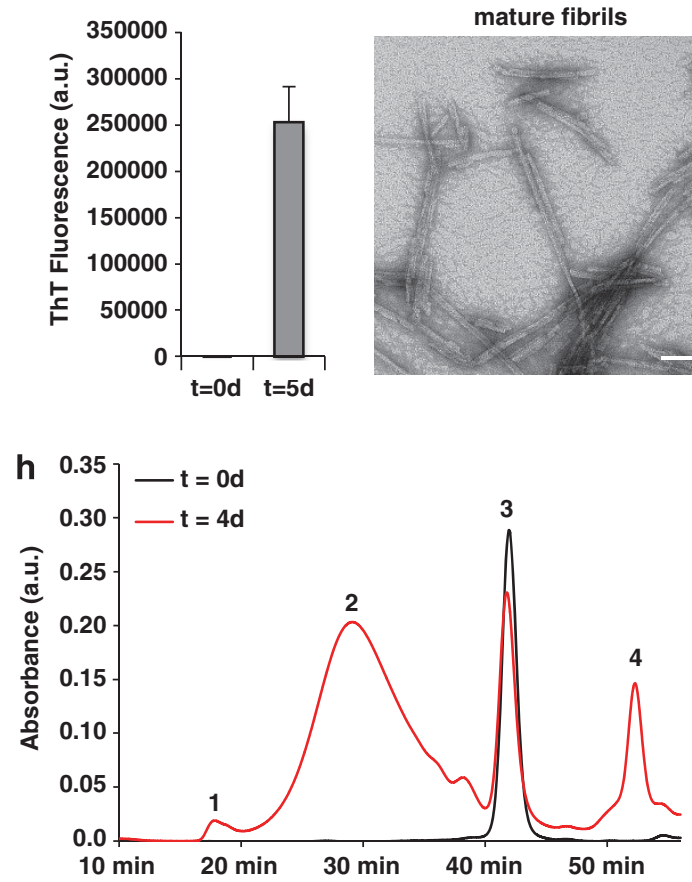

mature fibrils

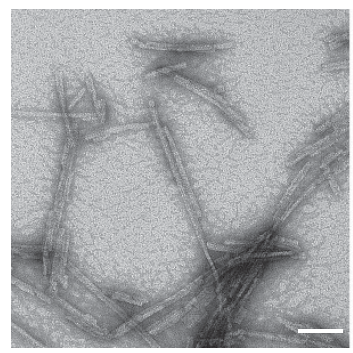

i

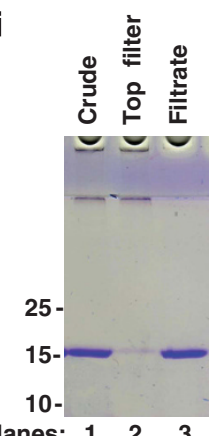

sonicated fibrils

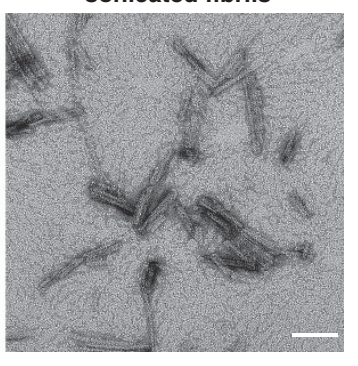

g

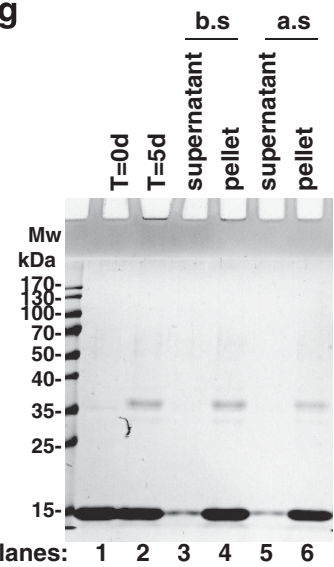

Figure 1 Preparation and characterization of recombinant monomeric, fibrillar and oligomeric $\alpha$-syn species. (a-c) Purity and characterization of $\alpha$-syn monomers. Recombinant WT human $\alpha$-syn was produced in $E$. coli and purified by anion exchange chromatography and size exclusion chromatography followed by a final chromatographic step using reverse-phase HPLC as previously described. ${ }^{28}$ To ensure that the monomeric preparation was free of oligomers and fibrils, the stock solutions were always filtered through $100 \mathrm{kDa}$ Amicon filters (a). The purity of recombinant monomeric $\alpha$-syn after purification was assessed by SDS-PAGE gel combined with Coomassie blue staining (a, lefthand panel) and WB analysis (a, right-hand panel), both of which showed a single band at $\sim 17 \mathrm{kDa}$. The purity of recombinant monomeric $\alpha$-syn after purification was also assessed by analytical reversed-phase ultra-HPLC analysis that showed a single peak (b) and confirmed by MALDI-TOF-MS that showed a mass of 14559.9 Da (c). The mass at $7233 \mathrm{Da}$ corresponds to the doubly charged species. (d-g) Purity and characterization of $\alpha$-syn fibrils. $\alpha$-Syn fibrils were formed by incubation of monomeric $\alpha$-syn for 5 days at $37^{\circ} \mathrm{C}$ under constant agitation of 1000 r.p.m. and fibrils formation was assessed by ThT fluorometry (d). All data represent average \pm S.D. $(n=3)$. Quality and characterization of $\alpha$-syn fibrils were assessed by TEM imaging (e) showing negatively stained full-length $\alpha$-syn fibrils with characteristic rigid nonbranched fibrillar morphology with a diameter of $\sim 10 \mathrm{~nm}$. In order to increase their solubility, homogeneity and their seeding potential, the mature fibrils were subjected to mild sonication that results in the fragmentation of the fibrils into shorter fibrillar fragments with an average length of $50-200 \mathrm{~nm}$, scale bar $=100 \mathrm{~nm}$ (f). As sonication of mature fibrils can lead to the release of small amounts of monomeric $\alpha$-syn, only preparations with residual levels of $\alpha$-syn monomers $<5 \%$ were used in our toxicity studies. Thus, the purity of $\alpha$-syn fibrils was finally verified by SDS-PAGE gel and Coomassie blue staining (g). More than $95 \%$ of the monomeric $\alpha$-syn is converted to $\alpha$-syn fibrils after 5 days of incubation, as shown after pelleting the nonsoluble fibrils by centrifugation and analyzing the supernatant (lanes 3 and 5 ) or the pellet (lanes 4 and 6 ) before sonication (b.s.; lanes 3-4) and after sonication (a.s.; lanes 5-6). (h-k) Purity and characterization of dopamine-induced $\alpha$-syn oligomers. (h) Chromatograms of Superose 6 purification of monomeric $\alpha$-syn (black curve) and dopamineinduced $\alpha$-syn oligomers formed by incubation of $\alpha$-syn $(140 \mu \mathrm{M})$ with 20 eq. of dopamine (red) for 4 days. Peak $3(42 \mathrm{~min})$ corresponded to the $\alpha$-syn monomer peak (14 kDa), whereas peak 1 ( $18 \mathrm{~min}$ ) corresponded to the void volume (size $>600 \mathrm{kDa}$ ). The broad peak 2 in between corresponded to oligomeric $\alpha$-syn species, whereas peak 4 (53 min) corresponded to excess dopamine. (i) After 4 days of incubation of $\alpha$-syn with 20 eq. of dopamine (lane 1), the sample was filtered through a 100-kDa filter. The remaining monomers were obtained in the filtrate (lane 3), whereas the oligomers remained on top of the filter (lane 2). SDS-PAGE analysis confirmed that the oligomers were free of monomers, as evidenced by the absence of a band at $\sim 15 \mathrm{kDa}$ (lane 2). The final concentration of $\alpha$-syn oligomers was determined by amino acid analysis. (j) Characterization of dopamine-induced $\alpha$-syn oligomers by TEM. TEM micrographs show mostly spherical/globular aggregates with a diameter between $20 \mathrm{and} 60 \mathrm{~nm}$. Scale bar $=100 \mathrm{~nm}$. (k) ThT fluorescence of dopamine-induced $\alpha$-syn oligomers. All data represent average \pm S.D. $(n=3)$. As previously reported in the literature, the ThT fluorescence signal of the dopamine-induced oligomers did not change over time, consistent with the absence of fibrils, as determined by TEM (j) $)^{22,31,67}$ 

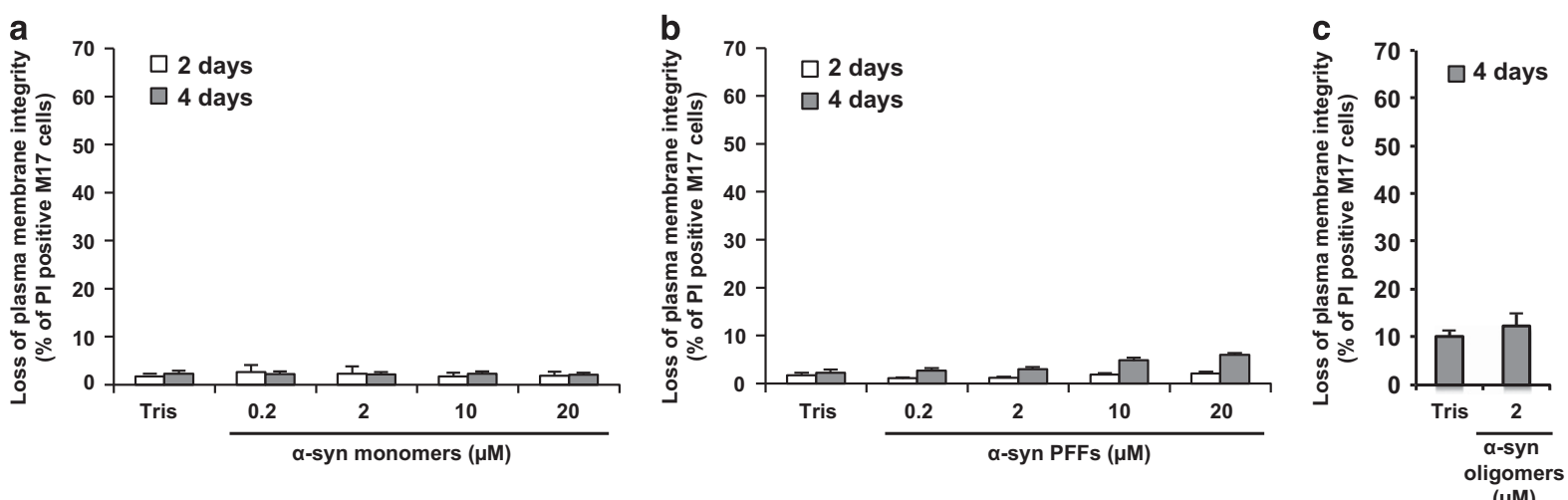

d

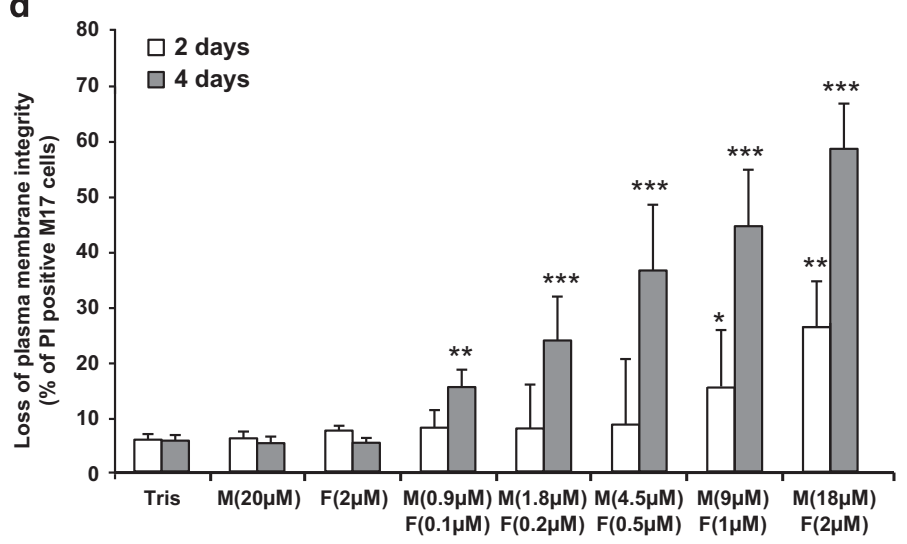

f

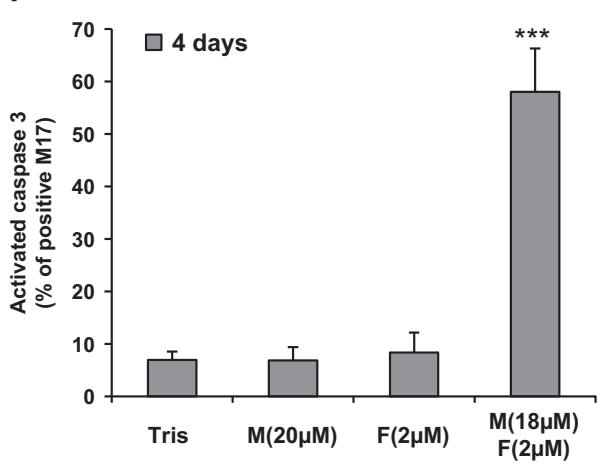

g

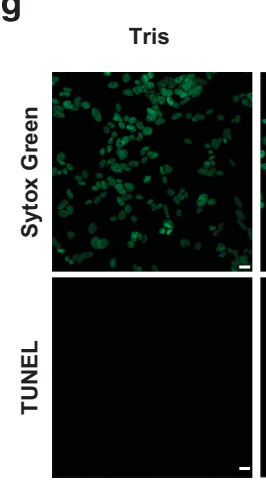

e

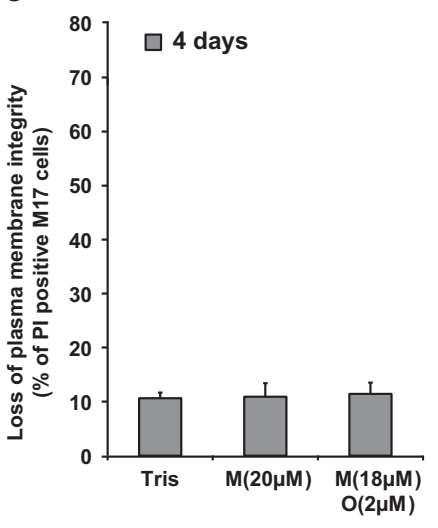

$M(20 \mu M)$

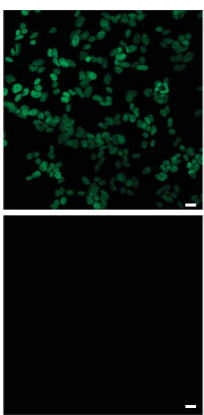

$F(2 \mu M)$

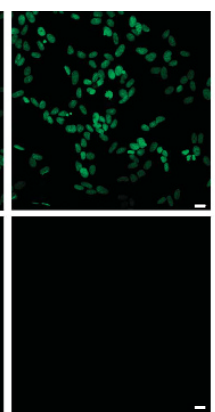

$M(18 \mu M)$ $\mathrm{F}(2 \mu \mathrm{M})$

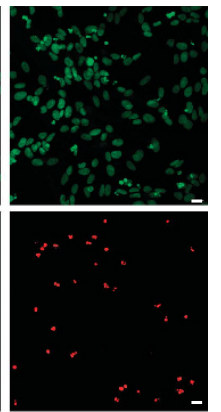

Figure 2 Mixture of $\alpha$-syn monomers and fibrils but not individual $\alpha$-syn species is toxic to M17 neuroblastoma cell line. (a-g) The human neuroblastoma M17 cells were treated with Tris buffer (50 mM Tris, pH 7.5, $150 \mathrm{mM} \mathrm{NaCl}$; negative control) or $\alpha$-syn monomers (M), sonicated $\alpha$-syn PFFs (F), $\alpha$-syn oligomers (O), $\alpha$-syn mixtures (M+O) or $(\mathrm{M}+\mathrm{F})$ for the indicated times. (a-e) Cells were harvested and stained with propidium iodide (PI), a membrane-impermeant dye that will enter only in cells with damaged plasma membranes. Cell death level is expressed as the percentage of cells with loss of plasma membrane integrity (PI-positive cells) to the total cell number analyzed by FACS. (f) Cells were harvested and caspase 3 activity was quantified by a caspase 3 activity assay using FACS. (g) Cells were fixed with PFA 4\% and subsequently stained for the apoptotic cells (TUNEL, red) and the nucleus was counterstained using Sytox Green (green). Scale bars $=10 \mu \mathrm{m}$. (a-f) Data shown represent the means of three independent experiments performed in triplicate for each condition (bars are means \pm S.D.). One-way ANOVA test followed by Tukey-Kramer post-hoc test were performed (Tris versus $\alpha$-syn-treated conditions), no statistical significance was observed in (a-c,e); ${ }^{*} P<0.01,{ }^{* *} P<0.001,{ }^{* \star *} P<0.0001$ in (d and f)

inhibitor of $\alpha$-syn fibrillization ${ }^{22}$ or by replacing monomeric $\alpha$ syn by $\beta$-synuclein ( $\beta$-syn), a close $\alpha$-syn homolog that lacks the NAC (non-A $\beta$ component) region, does not form fibrils ${ }^{36}$ and inhibits $a$-syn fibrillization and inclusion formation in vitro ${ }^{37}$ and in vivo, ${ }^{38}$ respectively. Remarkably, the addition of Tolcapone significantly reduced $a$-syn mixture-induced toxicity in both M17 cells and primary neurons, indicating that fibrillar growth contributes to the toxic event (Figure 5a and
Supplementary Figure S5A). Interestingly, the slight toxicity induced by $a$-syn PFFs alone in primary neurons was not significantly inhibited by Tolcapone, suggesting that $a$-syn PFFs could promote cell death by other mechanisms (Figure 5a). These findings are also consistent with nucleated polymerization-linked toxicity as Tolcapone is known to inhibit fibril growth without disrupting the preformed fibrils. ${ }^{22}$ Moreover, the substitution of monomeric $a$-syn by monomeric 
$\beta$-syn in the mixture composition did not promote any toxicity in primary neurons or in M17 cells (Figure $5 \mathrm{~b}$ and Supplementary Figure S5B), indicating that $a$-syn fibrillar growth and seeding capacity play key roles in mediating $a$-syn toxicity.
Previous studies have suggested that $a$-syn fibril formation could be seeded by fibrils derived from other amyloid-forming proteins in vitro, in primary neurons and in transgenic mice. ${ }^{38}$ To determine whether cross-seeding of $a$-syn could contribute
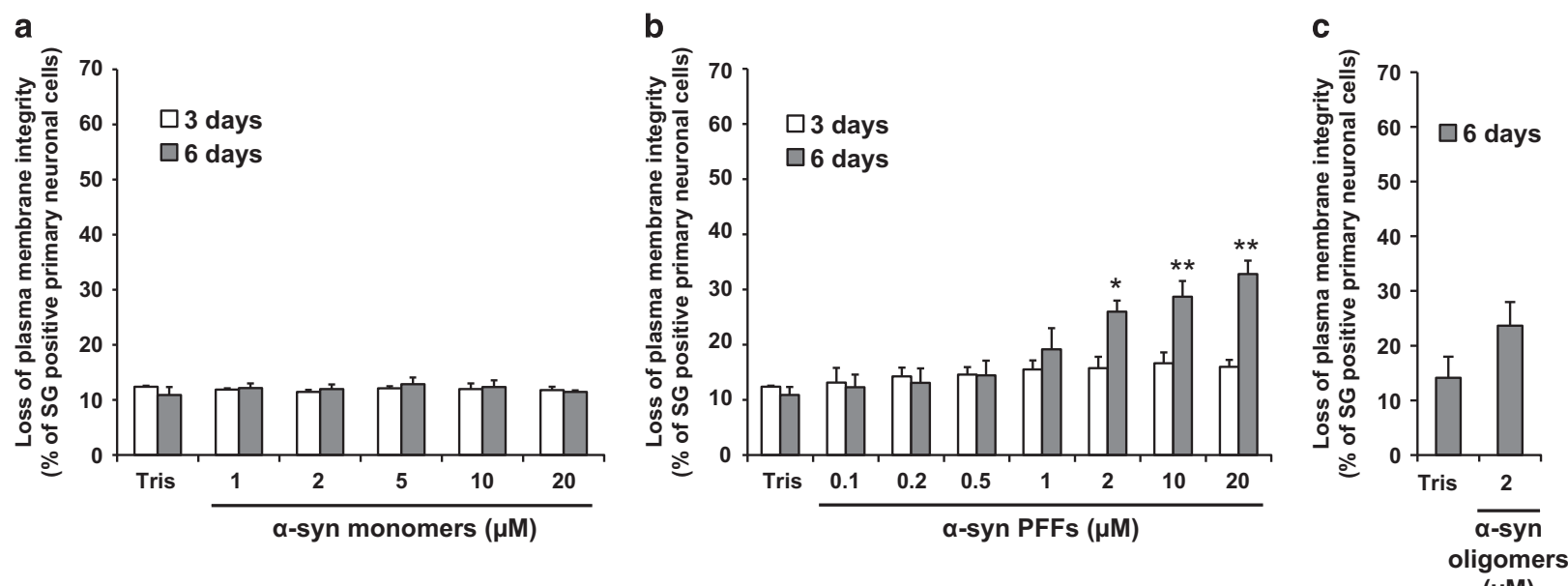

d

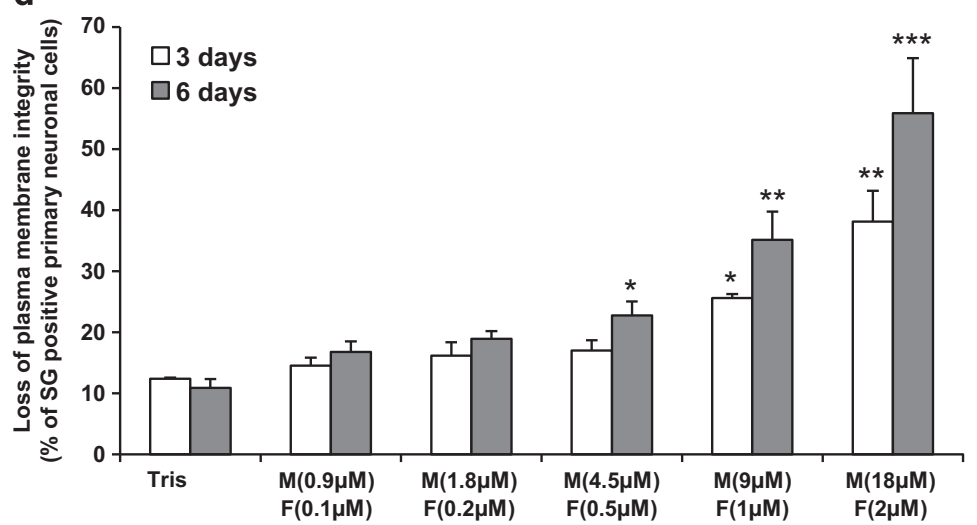

e

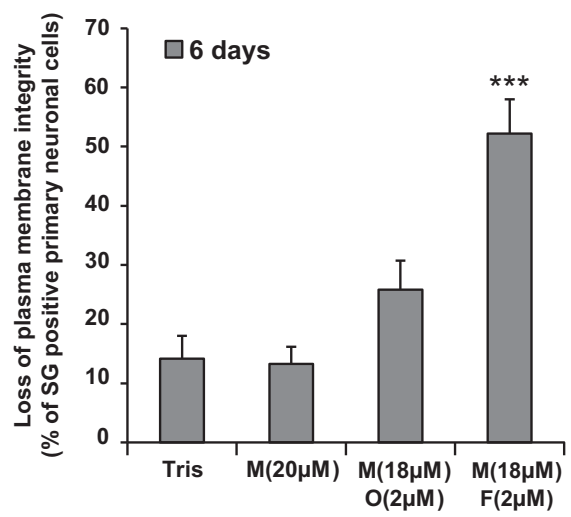

f

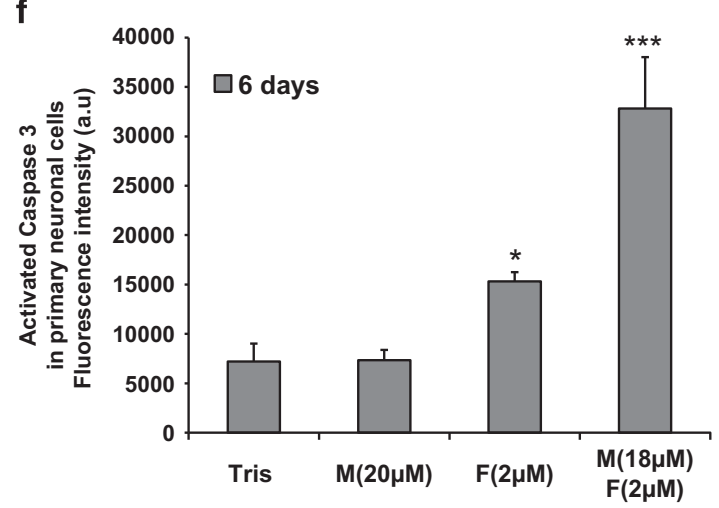

g

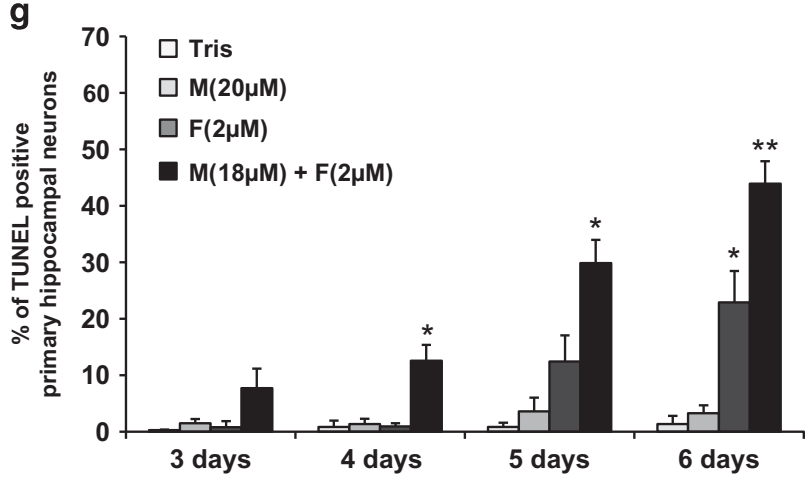

Figure 3 Mixture of $\alpha$-syn monomers and fibrils exacerbates cell death in hippocampal primary neurons. (a-f) Hippocampal primary neurons were plated in 96-well plate and treated with Tris buffer or $\alpha$-syn species for the indicated times. (a-e) Cells were stained with Sytox Green (SG), a membrane-impermeant dye that will enter only in cells with damaged plasma membranes. Cell death level is expressed as the percentage of cells with compromised cell membrane (SG-positive cells) to the total cell number analyzed by Tecan infinite M200 Pro plate reader $(487 \mathrm{~nm} / 519 \mathrm{~nm}$ ). (f) Caspase 3 activity was quantified by a caspase 3 activity assay using Tecan infinite M200 Pro plate reader $(487 \mathrm{~nm} / 519 \mathrm{~nm})$. (g) Hippocampal primary neurons were plated on coverslips and treated up to 6 days with Tris buffer (negative control), $\alpha$-syn monomers, sonicated $\alpha$-syn PFFs or $\alpha$-syn mixture. Cells were fixed at the indicated time with PFA 4\% and subsequently stained for the apoptotic cells (TUNEL). Nucleus was counterstained using SG and the neuronal population was specifically stained using NeuN. The percentage of apoptotic neurons was quantified as follows: (TUNEL-positive and NeuN-positive cells)/total NeuNpositive cells. Each experiment included counting of three fields with an average of 400 cells/field per condition. (a-g) Data shown represent the means of three independent experiments performed in triplicate for each condition (bars are means \pm S.D.). One-way ANOVA test followed by Tukey-Kramer post-hoc test were performed (Tris versus $\alpha$-syntreated conditions), no statistical significance was observed in (a-c); ${ }^{*} P<0.01,{ }^{* \star} P<0.001,{ }^{* \star} P<0.0001$ in (d, f and $\left.\mathbf{g}\right)$ 
a

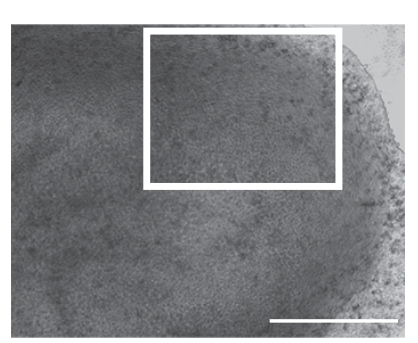

b
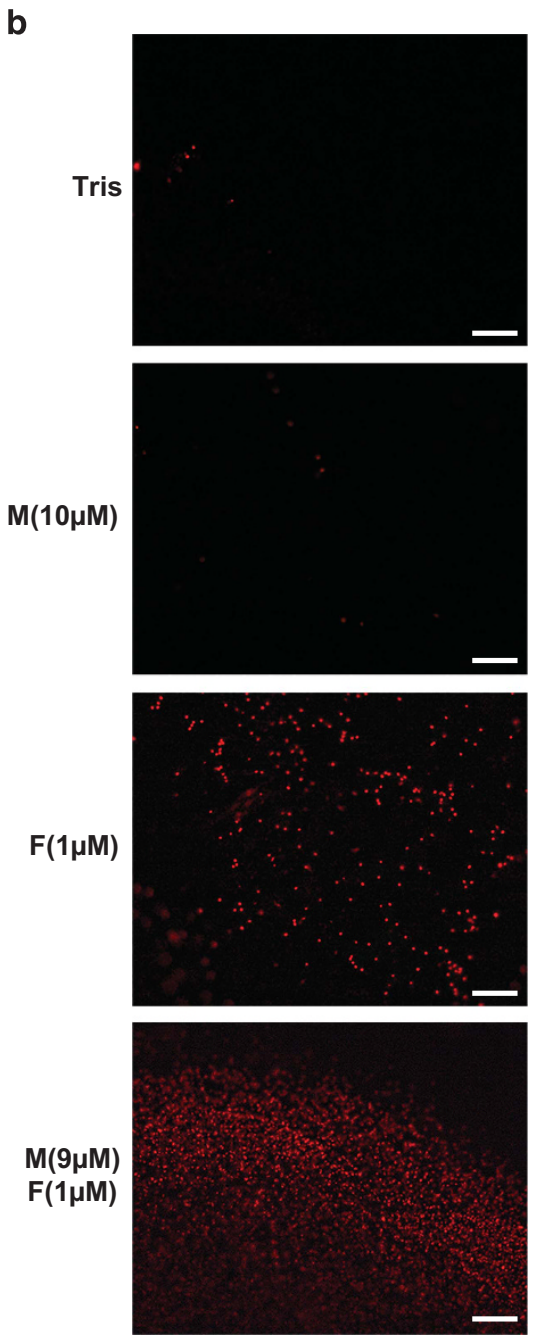

C

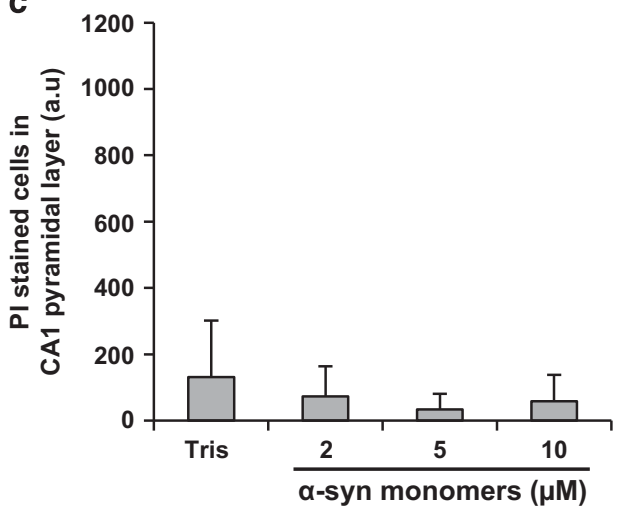

d

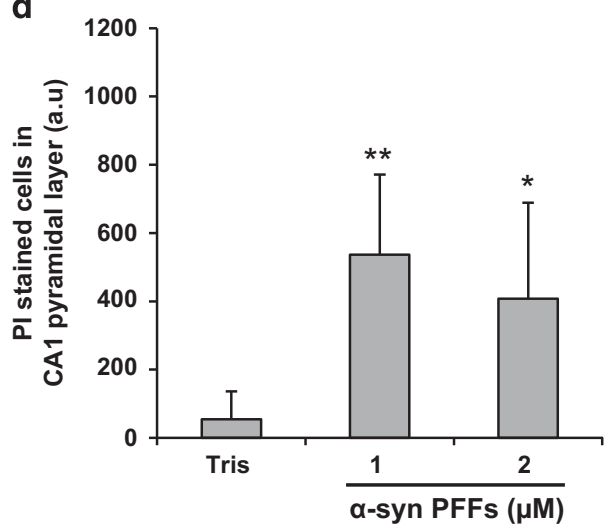

e

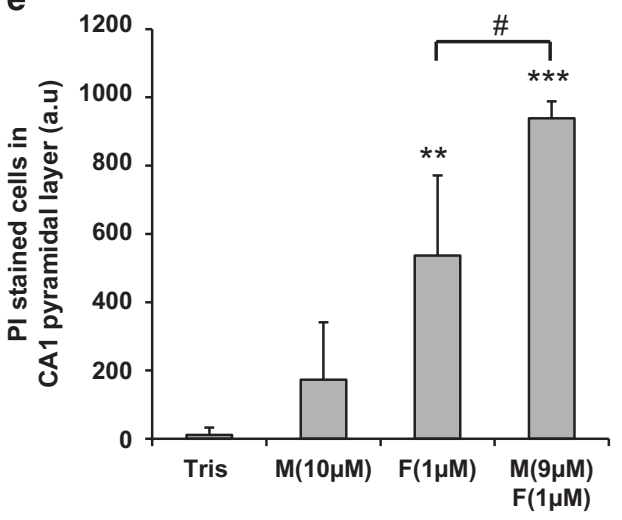

Figure 4 Mixture of $\alpha$-syn monomers and fibrils exacerbates cell death in ex vivo hippocampal slice culture. Hippocampal slices were treated at day in vitro (DIV) 13-14 with extracellular monomeric $\alpha$-syn, sonicated $\alpha$-syn PFFs or $\alpha$-syn mixture. After $24 \mathrm{~h}$, cell death was measured by quantification of PI-positive cells in the CA1 region. (a) Bright-field image of a hippocampal organotypic slice culture observed with a $5 \times$ objective. Insert indicates CA1 region of analysis shown in (b). Scale bars $=500 \mu \mathrm{m}$. (b) Epifluoresence images of CA1 area acquired under a $10 \times$ objective showing PI staining in different conditions of incubation: Tris, $\alpha$-syn monomers (M; $10 \mu \mathrm{M}), \alpha$-syn PFFs (F; $1 \mu \mathrm{M})$ and mixture of $\alpha$-syn monomers and PFFS $(9 \mu \mathrm{M} \mathrm{M}+1 \mu \mathrm{M} \mathrm{F})$. Scale bars $=100 \mu \mathrm{m}$. (c) Quantification of PI-positive cells in CA1 pyramidal layer after incubation of Tris ( $n=52$ cultures), $\alpha$-syn monomers at $2 \mu \mathrm{M}(n=39), 5 \mu \mathrm{M}(n=7)$ or $10 \mu \mathrm{M}(n=11)$. (d) Quantification of PI-positive cells in CA1 pyramidal layer after incubation of Tris $(n=29)$, PFFs at $1 \mu \mathrm{M}$ $(n=8)$ or $2 \mu \mathrm{M}(n=24)$. (e) Quantification of PI-positive cells in CA1 pyramidal layer after incubation of Tris $(n=4), \alpha$-syn monomers $10 \mu \mathrm{M}(n=4)$, PFFs $1 \mu \mathrm{M}(\mathrm{n}=8)$ and mixture of $\alpha$-syn monomers $(9 \mu \mathrm{M})$ and preformed fibrils $(1 \mu \mathrm{M})(n=8)$. (c-e) Bars are means \pm S.D. ${ }^{*} P<0.05,{ }^{* \star} P<0.001,{ }^{* \star} P<0.0001$ (Tris versus $\alpha$-syn-treated conditions), ${ }^{\#} P<0.01$ ( $\alpha$-syn PFFs versus $\alpha$-syn mixture), one-way ANOVA followed by Tukey-Kramer post-hoc test

to $a$-syn toxicity, we replaced $a$-syn PFFs in the mixture composition by Tau fibrils. Under these conditions, we did not observe any toxicity in primary neurons or in M17 cells (Figure 5b and Supplementary Figure S5B) or any seeding effect of Tau fibrils on the aggregation of monomeric $a$-syn in vitro (Supplementary Figure S6). Altogether, our data support the hypothesis that on-going aggregation and fibril growth events mediated by monomer addition play a major role in $a$-syn extracellular toxicity.

$a$-Syn fibrils attach at the cell plasma membrane and nucleate $\boldsymbol{a}$-syn aggregation. To better understand the 
a

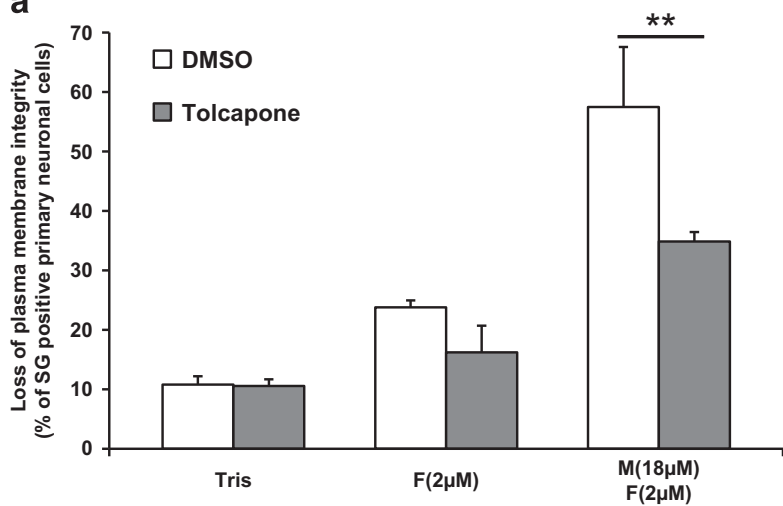

b

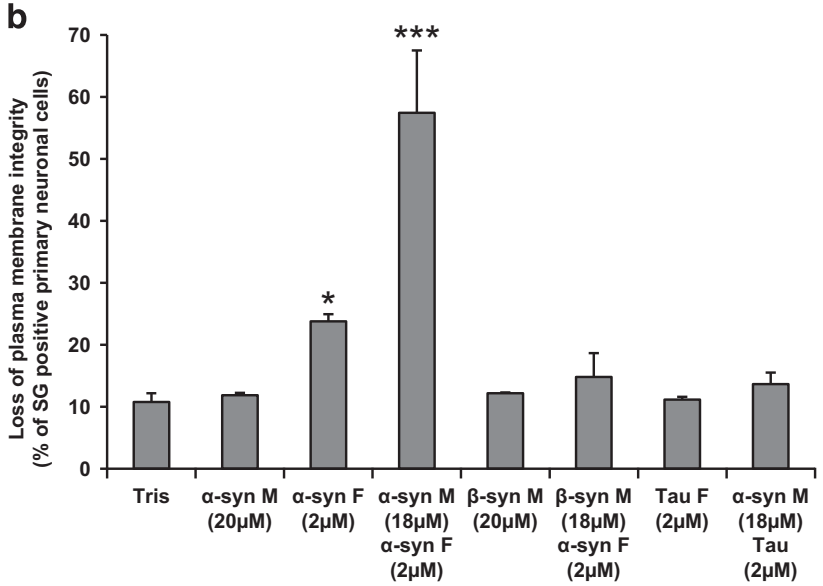

Figure 5 Inhibiting fibril growth attenuates $\alpha$-syn-induced toxicity in hippocampal primary neurons. Hippocampal primary culture were plated in 96-well plates and treated for 6 days with Tris buffer (negative control) or (a) the indicated $\alpha$-syn species in the presence of DMSO (negative control) or Tolcapone (aggregation inhibitor), (b) with $\beta$-syn monomers, a mixture of $\beta$-syn monomers and sonicated $\alpha$-syn PFFs, sonicated Tau PFFs or a mixture composed of $\alpha$-syn monomers and sonicated Tau PFFs. For each condition cells were stained with SG. Cell death level is expressed as the percentage of cells with compromised cell membrane (SG-positive cells) to the total cell number analyzed by Tecan infinite M200 Pro plate reader $(487 \mathrm{~nm} / 519 \mathrm{~nm})$. Shown are the means of three independent experiments performed in triplicate for each condition (bars are means \pm S.D.). One-way ANOVA test followed by TukeyKramer post-hoc test were performed, ${ }^{\star \star} P<0.001$ for $\alpha$-syn mixture \pm Tolcapone (a); ${ }^{\star} P<0.01,{ }^{\star \star \star} P<0.0001$. Tris versus $\alpha$-syn, $\beta$-syn or Tau-treated conditions (b)

mechanisms of $a$-syn aggregation-mediated cellular toxicity, we then investigated the subcellular localization of $a$-syn species by immunocytochemistry (ICC) staining or by live imaging using $a$-syn species unlabeled or fluorescently labeled (Supplementary Figure S7). In both cellular models, $a$-syn PFFs, but not a-syn monomers, were observed to associate with the plasma membrane (Supplementary Figures S8 and S9A). Interestingly, the addition of $a$-syn monomers to the PFFs resulted in the formation of an entangled network of $a$-syn aggregates that grew over time at the plasma membrane (Figure 6a and Supplementary Figures S8 and S9A) and that were positive for the proteostat dye that binds to the cross- $\beta$ spine quaternary structure of amyloidlike protein aggregates ${ }^{39-41}$ (Figure $6 \mathrm{~b}$ and Supplementary Figure S9B). These findings suggest that $a$-syn PFFs on the membranes may act as effective seeds and accelerate the fibrillization of monomeric $a$-syn. This may occur via primary or secondary nucleation events that could lead to (1) formation of additional fibrillar species, (2) formation of toxic oligomers or (3) disruption of the plasma membrane by either or both of these processes. Interestingly, total cell lysates analyzed by WB showed significant accumulation of $a$-syn aggregates on membranes and inside the cells only when cells were treated with $a$-syn mixture (Figures $6 \mathrm{c}$ and $\mathrm{d}$ and Supplementary Figures S9C and D). Under these conditions, the accumulation of higher-molecular-weight $a$-syn species was also observed, confirming the conversion of monomeric $a$-syn to stable oligomeric and fibrillar species (Figures $6 \mathrm{c}$ and $\mathrm{d}$ and Supplementary Figures S9C and D).

To provide more direct evidence for membrane association and disruption, we then used correlative light and electron microscopy (CLEM) (Supplementary Figure S10A) to visualize at ultrastructural level the accumulation and the fibrillization of $a$-syn species at the neuronal plasma membrane and to investigate how these dynamic processes could affect plasma membrane integrity. CLEM imaging confirmed that $a$-syn PFFs alone or combined with monomeric $a$-syn tightly bind to the plasma membrane of primary neurons (Figures $7 a$ and $b$ ). However, in the $a$-syn mixture condition, more fibrils associated and grew at the cell surface in a time-dependent manner (Figure $7 b$ ), leading to the formation of longer fibrils (Figures $7 \mathrm{~b}$ and $\mathrm{c}$ ). In addition, the presence of $a$-syn aggregates at the cell surface led to partial (PFFs alone) or total ( $a$-syn mixture) disruption of the plasma membrane at the latest time point (Figures $7 \mathrm{a}, \mathrm{b}$ and $\mathrm{d}$ ) compared with the control (Supplementary Figure S10B). Moreover, plasma membrane invaginations were detectable in the treated neurons at early time points (Figures $7 a$ and b).

Fibrillization-induced membrane disruption suggests the possibility that this process could increase the uptake of extracellular $a$-syn aggregates. Therefore, we investigated whether exogenous $a$-syn species could be internalized in the M17 cells over time using fluorescently labeled proteins with Oregon green (OG) or Alexa-fluor ${ }^{594}$ dyes (Supplementary Figure S7) combined with live flow cytometry quantification. We observed internalization of the PFFs (OG-F) at early time points $(\sim 4 \mathrm{~h})$ in cells treated with $a$-syn PFFs alone (green line), or with $a$-syn mixture (OG-F+monomers ${ }^{\mathrm{A594}}$ ) (purple line). However, no further accumulation of $a$-syn PFFs in the cells was observed at later time points (Supplementary Figure $\mathrm{S} 9 \mathrm{E})$. Conversely, $a$-syn monomers ${ }^{\mathrm{A} 594}$ were internalized and accumulated in cells in a time- and concentration-dependent manner (Supplementary Figure S9F, red line). Indeed, in the case of $a$-syn mixture, the presence of $a$-syn PFFs promoted the aggregation of monomeric $a$-syn at the plasma membrane (Supplementary Figure S9B), and these newly formed aggregates comprising a-syn monomers ${ }^{\mathrm{A} 594}$ were then internalized and accumulated in the cells (Supplementary Figure S9F, purple line).

Altogether, our data suggest that the toxic properties of a-syn mixture in cells might be linked to fibril deposition, growth and seeding capacity at the plasma membrane. However, given that $a$-syn is also internalized in cells, we cannot rule out the possibility that activation of intracellular pathways may also contribute to $a$-syn mixture-induced toxicity. Therefore, we next investigated the cell signaling pathways involved in the induction of cell death by $a$-syn 
a

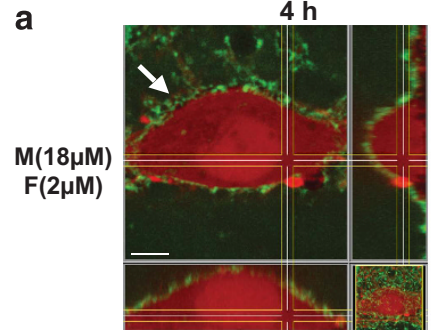

b
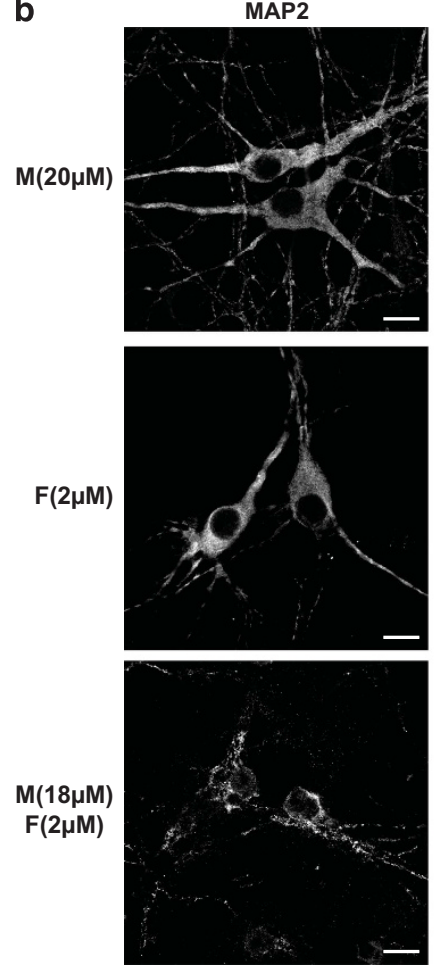

c

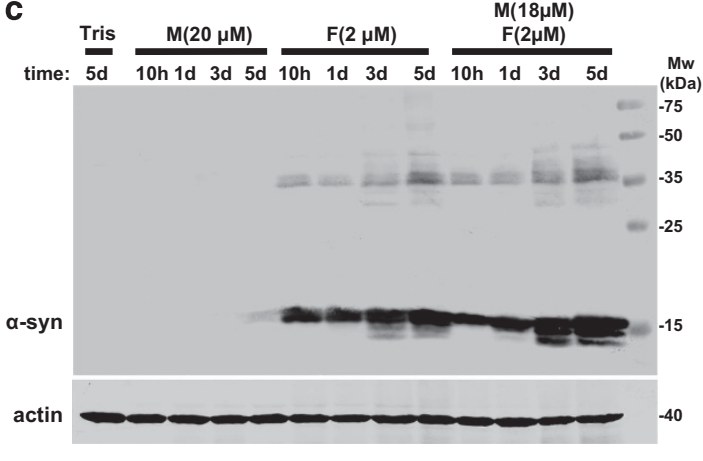

a-syn
$8 \mathrm{~h}$
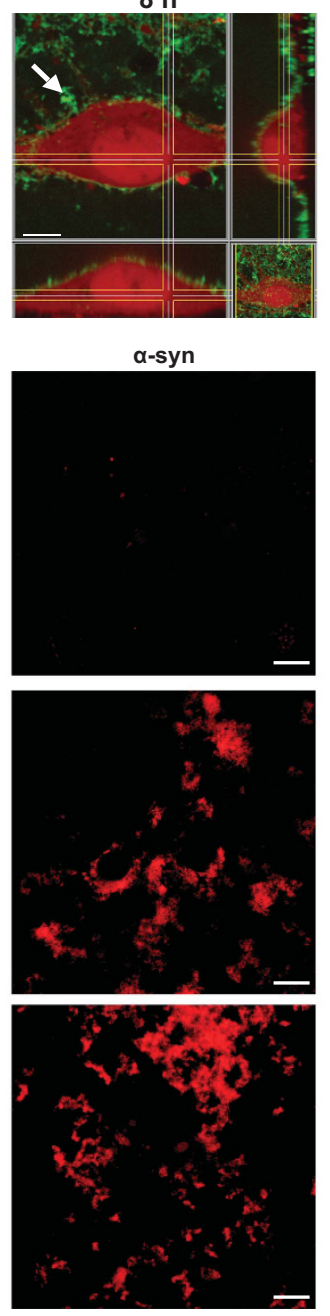

d

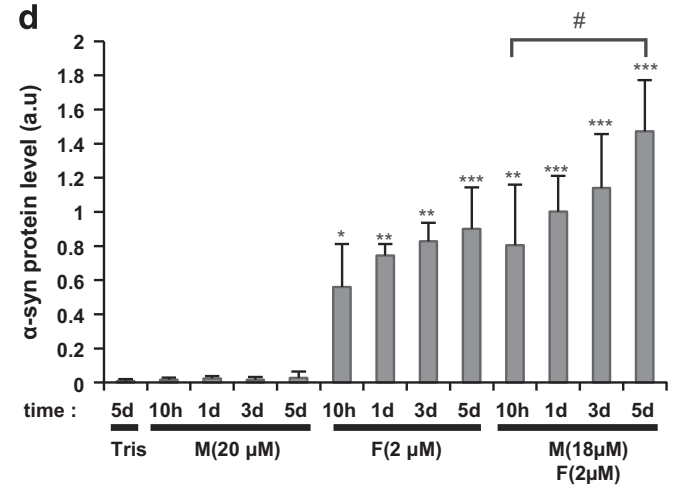

Figure $6 \alpha$-Syn mixture forms growing aggregates at the cell plasma membrane of hippocampal primary neurons. Hippocampal primary neurons were treated with Tris buffer (negative control) or $\alpha$-syn species for the indicated times. (a) Orthogonal projections of hippocampal primary neurons expressing dSRed (red) treated with a mixture of monomeric $\alpha$-syn labeled with Oregon Green (Supplementary Figure S7) and unlabeled fibrils for 4, 8, 12 and $24 \mathrm{~h}$. Arrows indicate a growing aggregate at the cell plasma membrane. Scale bars $=5 \mu \mathrm{m}$. (b) After 3 days, primary hippocampal neurons were washed 3 times before fixation, stained with the proteostat dye to specifically detect aggregates and immunostained against $\alpha$-syn (red) and against MAP2, a specific neuronal marker (gray). Scale bars $=10 \mu \mathrm{m}$. (c) Primary hippocampal neurons were washed three times to wash out the excess of proteins not attached to the cells. Primary hippocampal neurons were then lysed directly in LB $2 \times$ and boiled for 10 min before being loaded onto a 15\% SDS-PAGE gel and further analyzed by WB. $\alpha$-Syn protein level was detected as a main band at $\sim 15 \mathrm{kDa}$ using specific antibody. Accumulation of $\alpha$-syn at higher molecular weights was also observed and indicates the conversion of monomeric $\alpha$-syn into stable oligomeric or fibrillar states. Actin was used as a loading control. (d) Densitometry quantification of WB. Protein level of $\alpha$-syn was evaluated by densitometry quantification. Band intensities were normalized as follows: $\alpha$-syn/actin. Bars represent the mean \pm S.D. of three independent experiments. One-way ANOVA test followed by Tukey-Kramer post-hoc test were performed (Tris versus $\alpha$-syn-treated conditions): ${ }^{\star} P<0.01,{ }^{* \star} P<0.001,{ }^{* \star *} P<0.0001$ or $\left(\alpha\right.$-syn mixture $10 \mathrm{~h}$ versus 5 days) ${ }^{\#} P<0.01$ 
growth and fibrillization to understand specific mechanisms underlying $a$-syn-induced toxicity.

A mixture of $a$-syn monomers and fibrils initiates apoptosis in a caspase 8-dependent manner. Extracellular $a$-syn mixture led to the activation of both caspase 8 (initiator caspase activated in the extrinsic pathway) ${ }^{42}$ and caspase 9 (initiator caspase activated in the intrinsic pathway) $^{42}$ in primary neurons and in M17 cells (Figures $8 a$ and $b$ and Supplementary Figures S11A and B). $a$-Syn PFFs alone also induced the activation of the two initiator caspases but exclusively in the primary neurons (Figures $8 \mathrm{a}$ and $\mathrm{b}$ and Supplementary Figures S11A and B) and to a lesser extent than $a$-syn mixture. To determine which pathway was activated first, cells were treated for 4 days with the mixture of $a$-syn monomers and PFFs in the presence of specific caspase inhibitors. ZVAD-fmk (general caspase inhibitor) prevented the activation of caspase 8 (Figure $8 \mathrm{c}$ and Supplementary Figure S11C), caspase 9 (Figure 8d and Supplementary Figure S11D) and caspase 3 (Figure $8 e$ and Supplementary Figure S11E), and also protected cells against $a$-syn-induced toxicity (Figure $8 f$ and Supplementary Figure S11F). Interestingly, the specific inhibition of caspase 8 using IETD-fmk (Figure $8 \mathrm{c}$ and Supplementary Figure S10C) also significantly reduced the activation of caspase 9 (Figure 8d and Supplementary Figure S11D) and caspase 3 (Figure $8 \mathrm{e}$ and Supplementary Figure S11E) and decreased cell death induced by $a$-syn mixture by $\sim 50 \%$ (Figure $8 f$ and Supplementary Figure S11F). Conversely, specific inhibition of caspase 9 with LEHD-fmk (Figure 8d and Supplementary Figure S11D) neither changed the levels of activation of caspases 8 and 3 (Figures $8 \mathrm{c}$ and e and Supplementary Figures $\mathrm{S} 10 \mathrm{C}$ and $\mathrm{E}$ ) nor had any protective effect (Figure $8 \mathrm{f}$ and Supplementary Figure S11F). Altogether, these findings suggest that a mixture of $a$-syn PFFs and monomers could initiate apoptosis through the activation of the extrinsic pathway.

\section{Discussion}

Increasing genetic and pathophysiological evidence support the hypothesis that $a$-syn aggregation and fibril formation play a central role in the development of PD. Nevertheless, key questions regarding the nature of the toxic species, the role of the aggregation process itself or the cell death pathways involved in $a$-syn toxicity remain unanswered. Our study aimed at determining whether the dynamic of the fibrillization process itself, rather than isolated $a$-syn species, was the major contributor to extracellular $a$-syn-mediated toxicity.

To elucidate the relationship between $a$-syn aggregation state, fibril formation and toxicity, we developed highly standardized and reproducible protocols to prepare, isolate and fully characterize recombinant $a$-syn monomers (free of oligomers and fibrils), fibrils or oligomers (containing $<5 \%$ of monomeric $a$-syn). We showed that all three $a$-syn species were not toxic to the neuroblastoma cells when added individually. These findings are not in agreement with previous reports demonstrating increased cellular toxicity in neuroblastoma cell lines upon treatment with extracellular $a$-syn fibrils, and low toxicity level with $a$-syn monomers. ${ }^{22-25,43}$
It is noteworthy that the starting $a$-syn material used in these studies was not fully characterized, and that the ratio of monomeric to aggregated $a$-syn species was not assessed or reported. Therefore, we cannot rule out the possibility that the $a$-syn preparations used in these studies contained mixtures of monomers and aggregated forms (oligomers or fibrils) of $a$-syn. Another factor that could contribute to the discrepancies with our findings is that these studies relied solely on the MTT (3-(4,5-dimethylthiazol-2-yl)-2,5-diphenyltetrazolium bromide) assay which has been proven not to be reliable for assessing cell death $^{42}$ induced by the amyloid fibrils. ${ }^{34,45-47}$ To address this limitation, we assessed toxicity using several independent indicators of cell death including loss of membrane integrity, TUNEL staining and caspase 3, 8 and 9 activation.

In this study, we demonstrated that cell death occurs only under conditions that promote $a$-syn fibrillar growth and amyloid formation in neuroblastoma cell lines. In primary neurons and in ex vivo slices culture, $a$-syn PFFs alone induced some cell death. However, the toxicity was considerably increased when $a$-syn monomers were added to $a$-syn PFFs. $a$-Syn dopamine-stabilized oligomers that cannot convert to fibrils and lack seeding capacity did not exhibit significant toxicity. We expect that on-pathway oligomeric forms of $a$-syn would be more toxic as a result of their ability to convert to fibrils. These results further support our hypothesis that the nucleated polymerization process itself significantly contributes to cellular toxicity.

To test this hypothesis, we next investigated whether inhibiting fibril growth would significantly reduce or reverse $a$-syn toxicity. Indeed, our studies revealed that the inhibition of $a$-syn aggregation and fibril growth using a known inhibitor of $a$-syn fibrillization (e.g., Tolcapone) protected against $a$-syn mixture-induced toxicity. These findings are consistent with previous studies demonstrating that nucleated polymerization, which requires the presence of monomers, plays a central role in amyloid toxicity. For example, $A \beta 1-42$ exhibited higher toxicity as a crude mixture of monomers and oligomers compared with purified monomers, protofibrils or fibrils. ${ }^{33,34}$ Interestingly, primary neurons derived from a-syn knockout mice lacking endogenous $a$-syn exhibit protection against the toxicity of recombinant $a$-syn fibrils. ${ }^{14,17}$ Similarly, in scrapie disease, it was shown that the normal host protein $\operatorname{PrP}^{\mathrm{C}}$ is essential for the development of scrapie-induced neurotoxicity. ${ }^{48}$ In this study, we showed for the first time that the dynamic aggregation of full-length $a$-syn and its fibrillization are key mediators of $a$-syn-induced extracellular toxicity. However, the fact that PFFs alone could also induce toxicity in primary neurons and in ex vivo slice cultures suggests that extracellular $a$-syn fibrils could exert their toxicity via multiple cellular pathways.

Our results showed that $a$-syn fibrils, but not $a$-syn monomers, bind tightly to the cell plasma membrane and serve as nucleation sites for the aggregation of extracellular monomeric $a$-syn. Indeed, in the presence of $a$-syn PFFs, $a$-syn monomers in the culture media were converted into amyloid-like structures that accumulated at the plasma membrane of primary neurons. In the a-syn mixture condition, more fibrils associated and grew at the cell surface in a time-dependent manner, leading to the formation of longer fibrils and membrane disruption. This is consistent with 
a previous study of Holmes et al. ${ }^{49}$ showing that $a$-syn fibrils interact with the cell plasma membrane by binding to heparan sulfate proteoglycans. Both proteoglycans ${ }^{50,51}$ and lipids ${ }^{44,52,53}$ have been shown to accelerate and increase the aggregation propensity of $a$-syn in vitro, suggesting that these molecules may play important roles in mediating $a$-syn membrane interactions, fibril growth and toxicity. In addition, mature $a$-syn fibrils at the plasma membrane could also serve as secondary nucleation sites for $a$-syn oligomerization and fibril formation. ${ }^{54,55}$ This hypothesis is supported by recent findings, ${ }^{56}$ where the addition of A $\beta 1-42$ monomers to PFFs could lead to the formation of new fibrils with different structural and toxic
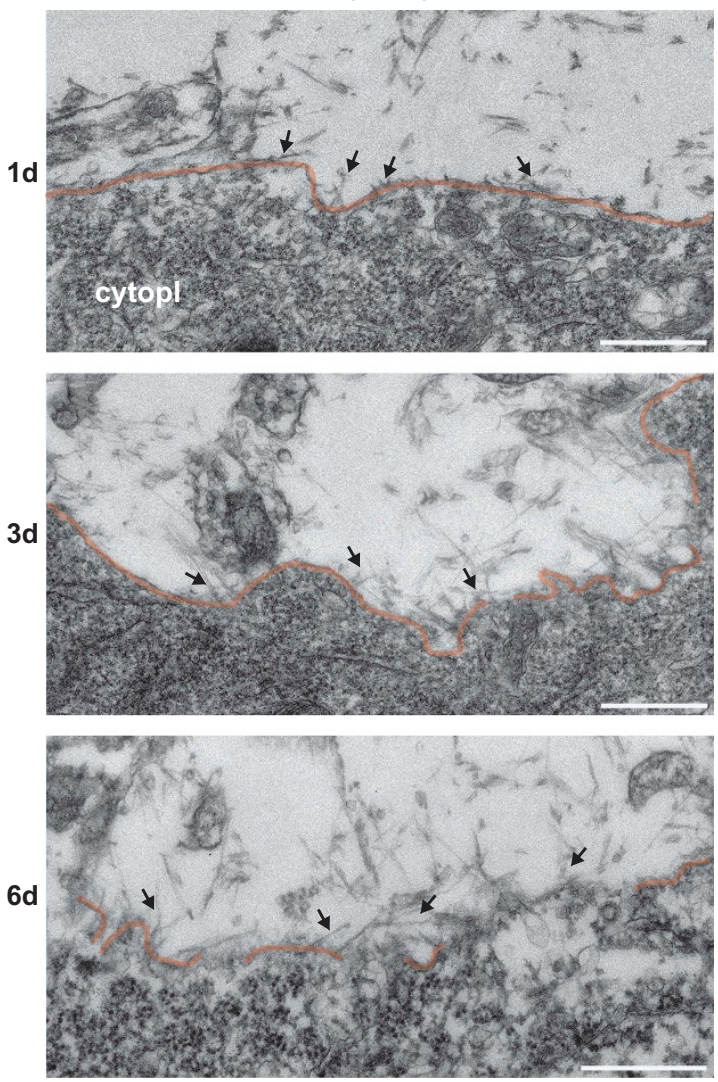

C

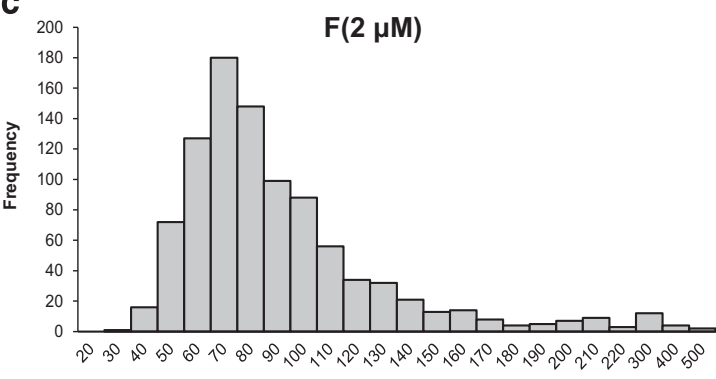

Fibrils length [nm] b
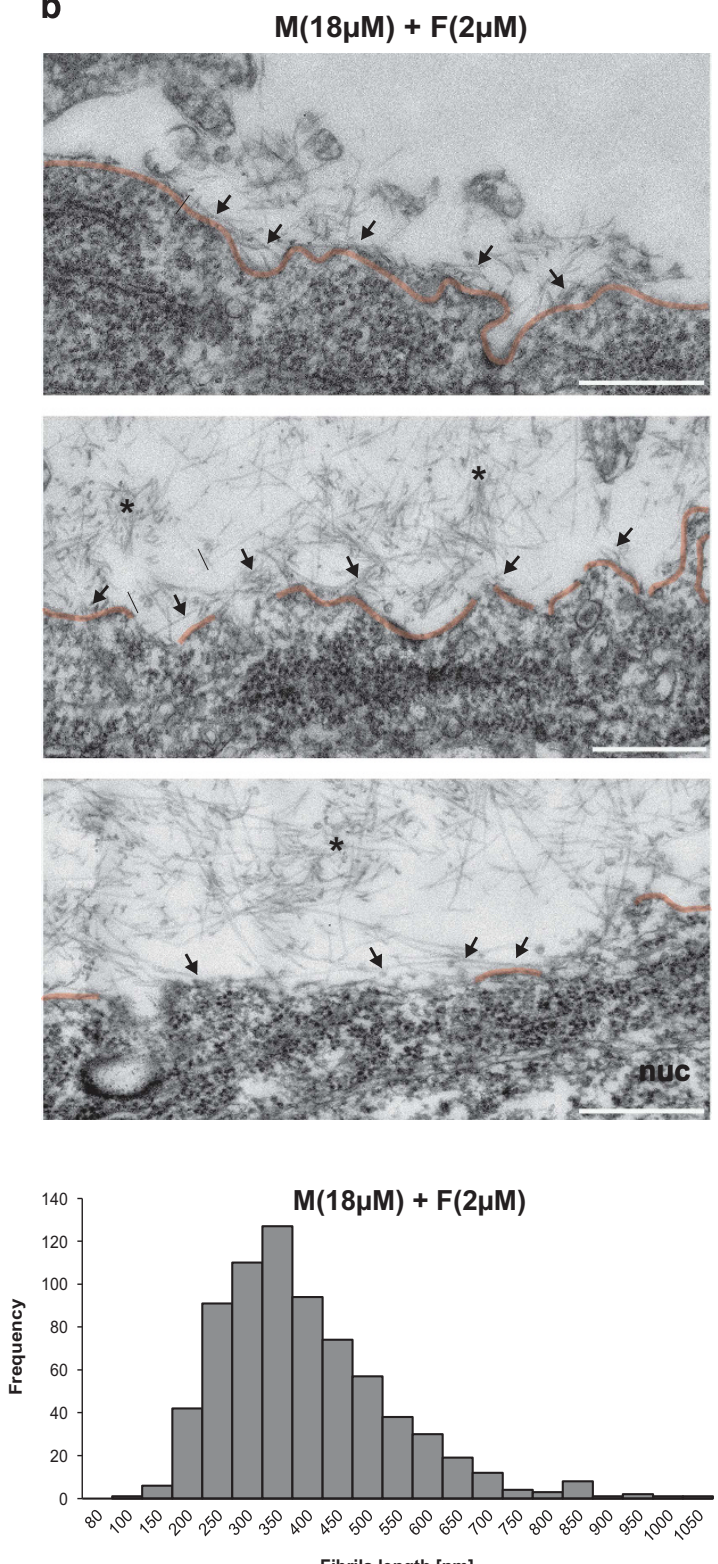

Fibrils length [nm]

d

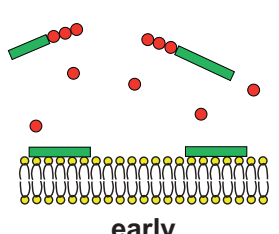

early

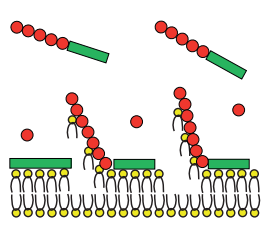

intermediate

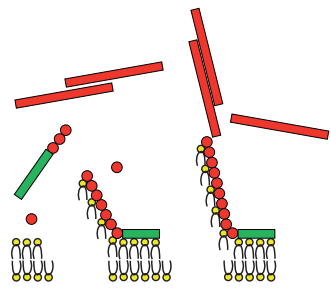

late 
a

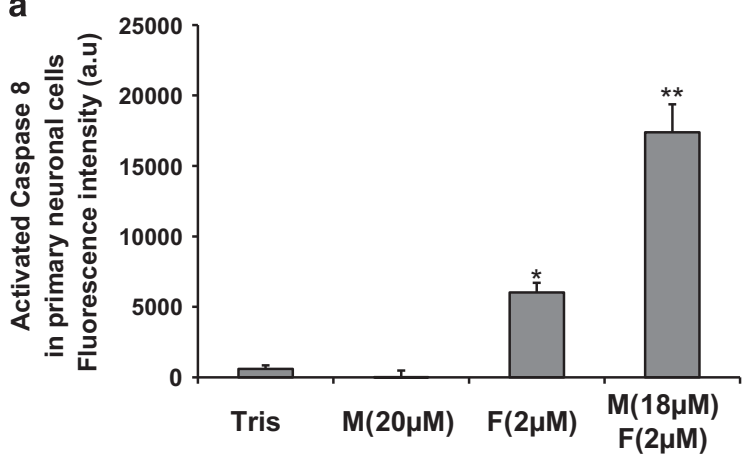

C

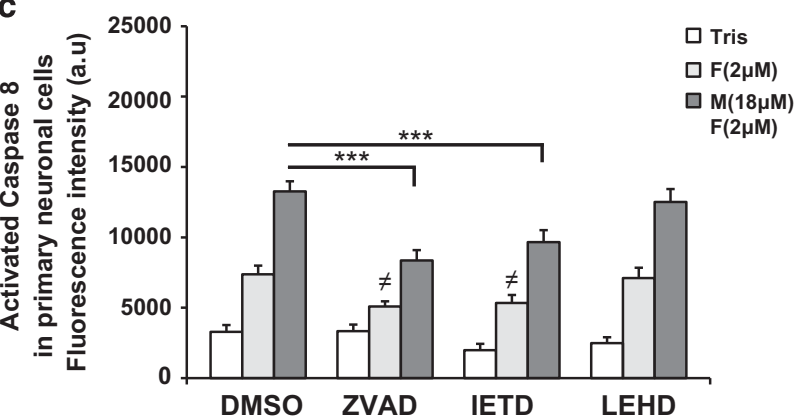

e

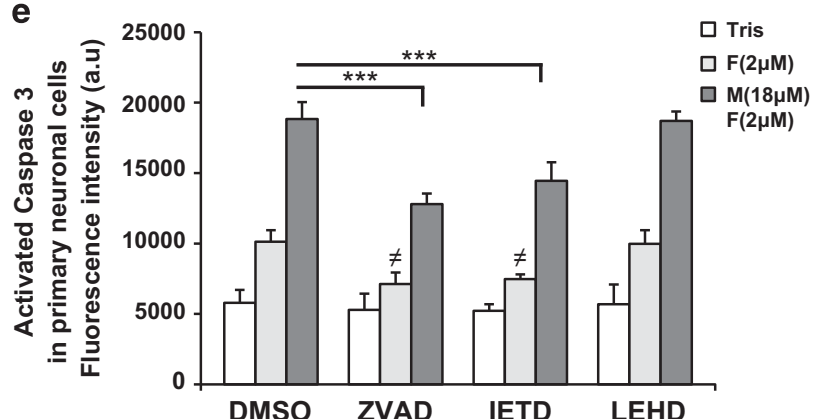

b

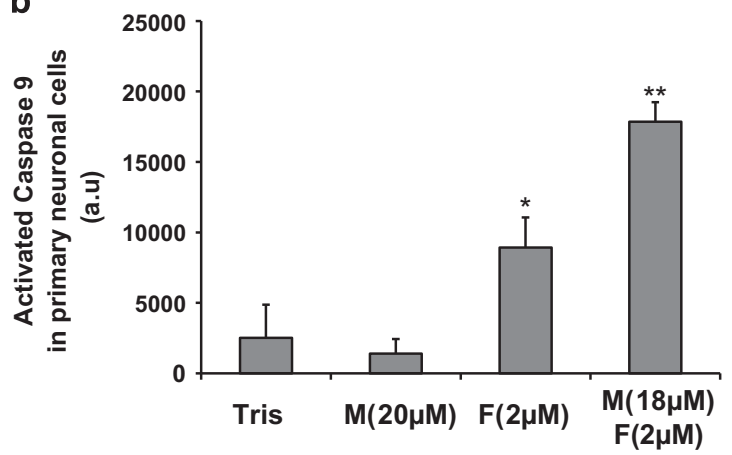

d

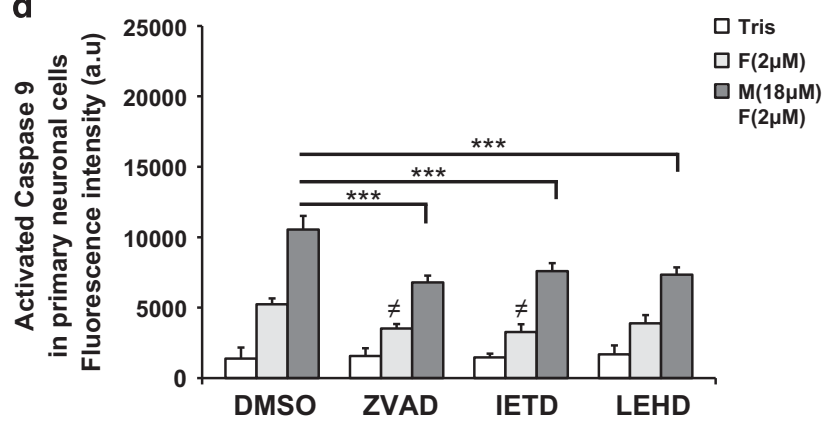

f

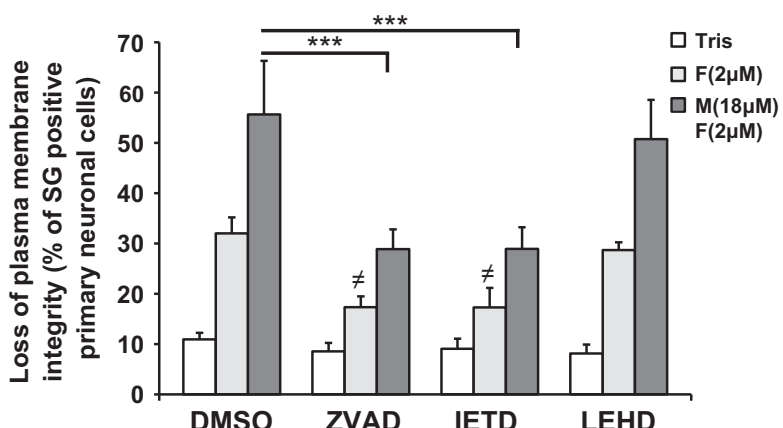

Figure 8 Mixture of $\alpha$-syn monomers and fibrils initiates apoptosis in a caspase 8-dependent manner in hippocampal primary neurons. (a-e) Hippocampal primary neurons were plated in 96-well plate and treated for 6 days with Tris buffer (negative control), $\alpha$-syn monomers, sonicated $\alpha$-syn PFFs or $\alpha$-syn mixture in the presence of DMSO (a and $\mathbf{b}$ ) or specific caspase inhibitors (c-f): IETD-fmk (caspase 8 inhibitor), LEHD-fmk (caspase 9 inhibitor), ZVAD-fmk a general caspase inhibitor or DMSO (as negative control). Caspase 8 activity (a and $\mathbf{c}$ ), caspase 9 activity (b and d) or caspase 3 (e) was quantified by respectively a specific caspase 8 or caspase 9 activity assay using fluorescent Tecan infinite M200 Pro plate reader $(487 \mathrm{~nm} / 519 \mathrm{~nm}$ ). (f) The level of cell death for each condition tested in (c-e) was also assessed using SG by Tecan infinite M200 Pro plate reader $(487 \mathrm{~nm} / 519 \mathrm{~nm})$. (a-f) Data shown represent the means of three independent experiments performed in triplicate for each condition (bars are means \pm S.D.). One-way ANOVA test followed by Tukey-Kramer post-hoc test were performed. (a and $\mathbf{b}$ ) (Tris versus $\alpha$-syn-treated conditions) ${ }^{\star} P<0.01,{ }^{\star *} P<0.001$; (c-f) ( $\alpha$-syn mixture+DMSO versus $\alpha$-syn mixture+caspase inhibitors) ${ }^{* * *} P<0.0001$ or $\left(\alpha\right.$-syn PFFs+DMSO versus $\alpha$-syn PFFs+caspase inhibitors) ${ }^{\neq} P<0.01$

Figure $7 \alpha$-Syn fibrils attach at the cell plasma membrane of hippocampal neurons and nucleate $\alpha$-syn aggregation (a and $\mathbf{b}$ ). Primary hippocampal neurons were seeded on special IBIDI dishes with alphanumerical searching grids imprinted on the bottom, allowing an easy localization of the cells when they was processed for TEM analysis. Cells were treated either with Tris buffer (negative control; illustrations are shown in Supplementary Figure S10), $\alpha$-Syn ${ }^{\mathrm{A} 594} \mathrm{PFFs}(2 \mu \mathrm{M})$ alone (left column) or with $\alpha$-syn mixture composed of $\alpha$-syn monomers $(18 \mu \mathrm{M})$ and $\alpha$-syn ${ }^{A 594}$ PFFs $(2 \mu \mathrm{M})$ mixture (right column) for 1 (1d), $3(3 \mathrm{~d})$ or 6 days (6d). Cells were first imaged with confocal microscopy and the selected neurons were further processed for TEM analysis. Shown are EM micrographs of the neurons of interest at 1d (top row), $3 \mathrm{~d}$ (middle row) and $6 \mathrm{~d}$ (bottom row). Fibrils of $\alpha$-syn interact with neuronal plasma membrane (arrows) in a time-dependent manner in both conditions. The neuronal plasma membrane is highlighted in orange. The presence of monomeric $\alpha$-syn in the mixture composition led to the formation of larger fibrillar aggregates (asterisk). In addition, the presence of $\alpha$-syn fibrils disrupted the plasma membrane as shown after extended treatment (3d and $6 \mathrm{~d}$ ). Scale bars $=0.5 \mu \mathrm{m}$; cytopl, cytoplasm; nuc, nucleus. (c) Histograms of the fibril length distribution of the $\alpha$-syn PFFs (left) compared with the $\alpha$-syn mixture (right). End-to-end measurement (955 for PFFs and 721 for Mixture) of the fibril length confirmed formation of shorter fibrils of the $\alpha$-syn PFFs alone with average length of $86.93 \pm 1.40 \mathrm{~nm}$ (S.E.) compared with the longer $\alpha$-syn mixture fibrils with average length of $370.69 \pm 5.33 \mathrm{~nm}$ (S.E.). (d) Schematic model based on the EM data of the interaction of $\alpha$-syn with the plasma membrane. Initially $\alpha$-syn PFFs (green rods) bind to the extracellular cell plasma membrane of the primary neurons and can serve as anchoring and nucleation points for the aggregation of extracellular monomeric $\alpha$-syn (red circles) at the cell plasma membrane. This fibrillization process could contribute to accelerate the disruption of the plasma membrane (middle panel). At the latest stage (right panel), in the presence of $\alpha$-syn mixture the integrity of the plasma membrane is completely disrupted and extensive $\alpha$-syn aggregates are formed (marked with an asterisk in $\mathbf{b}$ ) 
properties than those initially added to the cells.

To gain insights into the mechanisms by which $a$-syn PFFs or the newly formed aggregates could induce cellular toxicity, we investigated at the ultrastructural level how their localization at the cell surface could affect plasma membrane integrity. CLEM analysis revealed that the plasma membrane of the hippocampal primary neurons was totally disrupted after a few days in presence of $a$-syn mixture, whereas the deposition of PFFs led only to a partial disruption. The addition of $a$-syn monomers to the PFFs at the cell surface promotes the formation of a complex fibrillar network that compromises the plasma membrane integrity, as shown by the higher uptake of vital dyes with massive cell death as a consequence. Our data are in line with recent studies showing that interaction and aggregation of $a$-syn with lipid bilayers or vesicles in vitro leads to membrane disintegration ${ }^{52,57}$ and in vivo accumulation of extracellular $a$-syn at the surface of primary neurons perforates the plasma membrane leading to synaptic transmission defects and neuronal cell loss. ${ }^{58}$

Interestingly, newly formed $a$-syn aggregates following the addition of $a$-syn mixture to the culture media were internalized into M17 cells more rapidly than pure PFFs. These findings, combined with our CLEM data, suggest that the process of aggregation at the plasma membrane led to modifications and/ or partial disruption of the cell membrane, which in turn facilitates the internalization of $a$-syn fibrils, newly formed aggregates or even the uptake of $a$-syn monomers present in excess in the cell culture media. Once internalized, the different species of $a$-syn could have several deteriorating effects on the physiological condition of the neurons. Indeed, local increase of $a$-syn concentration in the neuronal cell bodies following uptake of extracellular $a$-syn could perturb the intracellular homeostasis of endogenous $a$-syn or could seed its aggregation. Therefore, the toxicity of $a$-syn mixture might not only be due to its capacity to aggregate at the plasma membrane, but also to its cellular uptake and activation of multiple toxic pathways.

To gain more insight into the mechanisms of $a$-syn toxicity, we determined which cell death pathways mediated $a$-syn aggregation-induced toxicity in our models. Using complementary approaches including TUNEL staining and caspases activation, we showed that $a$-syn mixture induces apoptosis. This is consistent with previous reports showing condensed and fragmented nuclei in SH-SY5Y cells when treated with aged solutions of recombinant $a$-syn, ${ }^{23}$ and in vivo caspase 3 activation in neurons exposed to extracellular $a$-syn aggregates from neighboring cells. ${ }^{12}$ In this study, we showed that both extrinsic and intrinsic pathways are activated by $a$-syn mixture. Although this is the exception rather than the rule, previous studies in cellular ${ }^{59}$ and in vivo $\mathrm{PD}$ models, ${ }^{60}$ together with post-mortem analysis of PD brains, ${ }^{60}$ similarly showed the activation of both caspases 8 and 9 . Importantly, we showed that the extrinsic pathway is activated first by $a$-syn aggregation, possibly through binding to receptors located at the plasma membrane.

Altogether, our data provide novel insights into the possible mechanisms by which extracellular $a$-syn and the dynamics of fibril formation could contribute to $a$-syn toxicity and PD pathology. On the basis of our data and published studies, we propose the following model (Supplementary Figure S12).
Fibrillar $a$-syn species, but not $a$-syn monomers, bind tightly to the plasma membrane and serve as nucleation sites for the aggregation of extracellular monomeric $a$-syn. The accumulation of these newly formed aggregates could induce toxicity through the disruption of the membrane induced by fibril growth on the membrane, leading to membrane thinning ${ }^{61}$ and disruption through sequestration of lipid molecules ${ }^{52,57}$ (Supplementary Figure S12A) or pore formation ${ }^{62}$ (Supplementary Figure S12B). It has been also postulated that secondary nucleation events could contribute to cellular toxicity by promoting the formation of highly toxic oligomeric species, ${ }^{54-56}$ although the mechanisms by which these species induce toxicity and whether or not they act directly on membrane receptors remain unknown (Supplementary Figure S12C1). During this dynamic aggregation process, the growing $a$-syn fibrils might directly bind to specific cell surface receptor molecules, leading to the activation of cell death signaling pathways (Supplementary Figure S12C2). Therefore, small-molecule drugs or conformational antibodies that directly target fibrils or inhibit fibrillar growth and secondary nucleation events could provide viable therapeutic strategies for the treatment of PD and other synucleinopathies. Finally, our work underscores the importance of developing novel tools to characterize $a$-syn species within the complex environment of the cell plasma membrane and to advance our understanding of the mechanisms of extracellular $a$-syn toxicity.

\begin{abstract}
Materials and Methods
Antibodies and compounds. Monoclonal anti- $\alpha$-syn (Syn-1) was purchased from BD Biosciences (Allschwil, Switzerland). Anti- $\alpha$-syn (211), anti- $\alpha$-syn (FI-140) and anti- $\beta$-catenin were obtained from Santa Cruz ((LabForce AG, Muttenz, Switzerland). Monoclonal $\beta$-actin was from Abcam (Cambridge, UK). Monoclonal MAP2 was from Sigma-Aldrich (Buchs, Switzerland). Monoclonal NeuN was from Millipore (Schaffhausen, Switzerland). Secondary antibodies goat anti-mouse Alexa $^{405}$, donkey anti-mouse Alexa ${ }^{488}$, donkey anti-rabbit Alexa ${ }^{568}$, donkey antirabbit Alexa ${ }^{647}$, donkey anti-mouse Alexa ${ }^{647}$ and goat anti-rabbit Alexa ${ }^{680}$ were purchased from Life Technologies (Zug, Switzerland). The secondary antibody goat anti-mouse IgG IRDye ${ }^{800 C W}$ was obtained from Li-Cor Biosciences GmbH (Bad Homburg, Germany). Tolcapone (aggregation inhibitor) was purchased from SigmaAldrich. ZVAD-fmk (general caspase inhibitor), IETD-fmk (caspase 8 inhibitor) and LEHD-fmk (caspase 9 inhibitor) were from Enzo Life Sciences (Lausen, Switzerland).
\end{abstract}

DNA constructs. Human $\alpha$-syn, $\beta$-syn and V16C- $\alpha$-syn were subcloned in the pT7-7 plasmids. Palmitoylation domain of neuromodulin-YFP was a gift from Professor Rémy Sadoul (UJF, Grenoble, France). The longest tau isoform (tau441) cloned into the $\mathrm{pET}-15 \mathrm{~b}$ expression vector was a gift from Dr. Eliezer, Weill Cornell Medical College (New York, NY, USA).

Expression and purification of $\alpha$-syn, $\beta$-syn and V16C- $\alpha$-syn. pT7-7 plasmids were used for the expression of recombinant human $\alpha$-syn and $\beta$-syn in E. coli. Human WT $\alpha$-syn and $\beta$-syn were expressed and purified by anion exchange chromatography (AEC) and SEC as described in detail by Fauvet et $a^{2 .}{ }^{28}$ $\alpha$-Syn was further purified via reverse-phase HPLC (Waters 600 system, BadenDättwil, Switzerland) using a Cosmosil C4 preparative column $(20 \mathrm{~mm} \times 250 \mathrm{~mm}$, 38048 ) with a linear gradient of $20-70 \%$ B (solvent $\mathrm{A}: \mathrm{H}_{2} \mathrm{O} / 0.1 \%$ formic acid, solvent B: acetonitrile/ $0.1 \%$ formic acid). $\alpha$-Syn elution was monitored by UV absorbance at 214 and $280 \mathrm{~nm}$ and the mass was confirmed by MALDI-TOF-MS and ESI-MS (Thermo Scientific, Reinach, Switzerland) analysis and SDS-PAGE. Acetonitrile was removed from the $\alpha$-syn-containing fractions using a rotary evaporator and the $\alpha$ syn fractions were lyophilized and stored at $-20^{\circ} \mathrm{C}$ until further use. The same procedure was followed for the expression and purification of $\mathrm{V} 16 \mathrm{C}-\alpha$-syn; however, potential disulfide bonds were reduced by the addition of tris (2-carboxyethyl)- 
phosphine hydrochloride (TCEP, Sigma-Aldrich) before the SEC and RP-HPLC purification steps. To ensure that the monomeric preparation was free of oligomers and fibrils, the stock solutions were always filtered through $100 \mathrm{kDa}$ Amicon filters (Millipore).

Fluorescent labeling of V16C- $\boldsymbol{\alpha}$-syn. Recombinant V16C- $\alpha$-syn was dissolved in $200 \mathrm{mM}$ of Tris, pH 7.0 (Trizma hydrochloride solution, Sigma-Aldrich). Subsequently, two equivalents (final conc. $200 \mu \mathrm{M}$ ) of TCEP (Sigma-Aldrich) were added to the protein solution and incubated at room temperature (RT) for $5 \mathrm{~min}$. OG maleimide, Alexa-fluor ${ }^{594}$ maleimide or Alexa-fluor ${ }^{647}$ maleimide (Life Technologies) were then added to the protein solution at a final concentration of $500 \mu \mathrm{M}$ (5 equivalents). The reaction was followed by ESI-MS and within $1 \mathrm{~h}, 95 \%$ of the V16C- $\alpha$-syn was conjugated with the maleimide compound. The free dye was separated from the labeled $\alpha$-syn with the PD10 gel filtration column (Fisher Scientific AG, Lucens, Switzerland) following the manufacturer's instructions. Briefly, the column was equilibrated with $50 \mathrm{ml}$ of $\mathrm{H}_{2} \mathrm{O}$ and the protein solution diluted to $2.5 \mathrm{ml}$ was added on top of the column and eluted with $\mathrm{H}_{2} \mathrm{O}$. After collection, $\alpha$-syn fractions were identified by SDS-PAGE and then combined and lyophilized. Correct mass of labeled $\alpha$-syn was determined by MALDI-TOF-MS and ESI-MS analyses. Purity was further confirmed by SDS-PAGE analysis in combination with UV spectroscopy.

Preparation of $\alpha$-syn fibrils. $\alpha$-syn fibrils were formed by incubating $500 \mu$ l of filtered ( $100 \mathrm{kDa}$ filter; Millipore) monomeric $\alpha$-syn solution ( $50 \mathrm{mM}$ Tris, $150 \mathrm{mM}$ $\mathrm{NaCl}$, pH 7.5) under constant orbital agitation (1000 r.p.m.; Peglab, Thriller, Germany) at $37^{\circ} \mathrm{C}$ for 5 days. ${ }^{28}$ Labeled $\alpha$-syn fibrils were made from $95 \%$ of unlabeled monomeric $\alpha$-syn solution and $5 \%$ of labeled monomeric $\alpha$-syn solution. The fibrils were mechanically reduced in size by sonication on ice (Sonics VibraCell, Newtown, CT, USA) with a fine tip for $5 \mathrm{~s}$ at an amplitude of $40 \%$. Note that sonication of $\alpha$-syn fibrils is a crucial step and should be carefully conducted in order to have sufficient breakage of the mature fibrils into smaller seeds, with a minimum release of $\alpha$-syn monomers. Sonicated $\alpha$-syn fibrils were aliquoted, snap frozen in liquid nitrogen and stored at $-80^{\circ} \mathrm{C}$. An aliquot of the sonicated fibrils was diluted 4 times in aggregation buffer $(50 \mathrm{mM}$ Tris, $150 \mathrm{mM} \mathrm{NaCl}, \mathrm{pH}$ 7.5) before characterization.

Characterization of $\alpha$-syn fibrils by TEM. The formation of $\alpha$-syn fibrils was verified by TEM as previously described by Fauvet et al. ${ }^{28}$ Briefly, $10 \mu \mathrm{l}$ of $\alpha$-syn fibrils were deposited on Formvar-coated 200 mesh copper grids (Electron Microscopy Sciences, Hatfield, PA, USA). After two washes with double-distilled $\mathrm{H}_{2} \mathrm{O}$, grids were stained with uranyl formate $0.7 \%$ (w/v; Electron Microscopy Sciences, Hatfield, PA, USA) followed by vacuum drying from the edge of the grids. Specimens were examined using Tecnai Spirit TEM (FEl, Eindhoven, The Netherlands) operating at $80 \mathrm{kV}$ of acceleration voltage and equipped with bottommounted 4k $\times 4 k$ Eagle CCD camera controlled by TIA acquisition software (FEI).

Characterization of $\boldsymbol{a}$-syn fibrils by ThT. The extent of fibril formation and amyloid-like properties of a-syn aggregates were assessed by ThT fluorescence as explained previously. ${ }^{28}$ Briefly, sonicated $\alpha$-syn fibrils were resuspended in ThT solution (50 mM glycine, $\mathrm{pH} 8.5,10 \mu \mathrm{M}$ ThT solution) and loaded as triplicate in a black 384-well plate (Nunc, Roskilde, Denmark). The plates were agitated under orbital shaking for $5 \mathrm{~min}$ to homogenize the samples and ThT fluorescence was measured with a TECAN spectrometer (Bucher Biotek, Basel, Switzerland) at an excitation wavelength of $450 \mathrm{~nm}$ and an emission wavelength of $485 \mathrm{~nm}$.

Characterization of $a$-syn fibrils by SDS-PAGE and Coomassie blue staining. The presence of residual soluble $\alpha$-syn in the sonicated $\alpha$-syn fibril solution was assessed by SDS-PAGE analysis in combination with Coomassie blue staining. Residual monomeric $\alpha$-syn was assessed by filtering the $\alpha$-syn fibril solution through a $100-\mathrm{kDa}$ filter. After filtration, $20 \mu \mathrm{l}$ of the filtrate was sampled and resuspended in $20 \mu$ l of $2 \times$ Laemmli Buffer (LB) (2\% SDS, $20 \%$ glycerol, $0.05 \%$ bromophenol blue, $0.125 \mathrm{M}$ Tris- $\mathrm{HCl}, \mathrm{pH} 6.8$, and $5 \% \beta$-mercaptoethanol). The amount of soluble $\alpha$-syn in the $\alpha$-syn fibril solution was assessed by high-speed centrifugation. Then, $40 \mu \mathrm{l}$ of sonicated $\alpha$-syn fibril solution was centrifuged at $20000 \times g$ for $30 \mathrm{~min}$ at $4^{\circ} \mathrm{C}$. Next, $20 \mu \mathrm{l}$ of supernatant was carefully sampled and resuspended in $20 \mu \mathrm{l}$ of $2 \times$ LB. The rest of the supernatant was removed and the pellet with sonicated fibrils was resolubilized in $40 \mu$ l of aggregation buffer. Resolubilized pellet $(20 \mu \mathrm{l})$ was resuspended in $20 \mu \mathrm{l}$ of $2 \times$ LB. Samples were boiled for $10 \mathrm{~min}$ at $95{ }^{\circ} \mathrm{C}$ before being loaded on a $15 \%$ polyacrylamide SDS-PAGE gel and stained by Coomassie Brilliant Blue R-450 solution (Life Technologies). As sonication of mature fibrils can lead to the release of small amounts of monomeric $\alpha$-syn, only preparations with residual levels of $\alpha$-syn monomers $<5 \%$ were used in our toxicity studies.

Preparation and characterization of dopamine-induced $a$-syn oligomers. Recombinant $\alpha$-syn was dissolved in $20 \mathrm{mM}$ Tris, $\mathrm{pH} 7.4$, and $100 \mathrm{mM} \mathrm{NaCl}$ to a final concentration of $140 \mu \mathrm{M}$, the $\mathrm{pH}$ was readjusted to $\mathrm{pH} 7.5$ with $\mathrm{NaOH}$ and the protein solution was filtered through a $100-\mathrm{kDa}$ filter. After addition of 20 equivalents of dopamine $(2.8 \mathrm{mM})$, the $\alpha$-syn solution was incubated at $37^{\circ} \mathrm{C}$ under constant orbital shaking (200 r.p.m.) for 4 days.

The formation of oligomers was monitored by gel filtration chromatography. Samples were applied at a concentration of $35 \mu \mathrm{M}$ onto a Superose $610 / 300 \mathrm{GL}$ column (Fisher Scientific AG) equilibrated with $50 \mathrm{mM}$ Tris, $150 \mathrm{mM} \mathrm{NaCl}, \mathrm{pH} 7.5$, and eluted at a flow rate of $0.4 \mathrm{ml} / \mathrm{min}$, using an Agilent 1200 series HPLC pump (Agilent, Santa Clara, CA, USA). The elution of the protein was monitored by UV absorbance at $280 \mathrm{~nm}$ (Agilent 1200 VWD, Agilent). $\alpha$-Syn oligomers were characterized by EM, ThT staining and SDS-PAGE analysis.

The $\alpha$-syn oligomers in the crude mixture (Figure 1i, crude) were separated from the residual monomer (Figure 1i, filtrate) by filtration of the protein solution through a $100-\mathrm{kDa}$ filter (Vivascience, Fisher Scientific, Loughborough, UK). The $\alpha$-syn oligomers, retained on the top of the filter (Figure 1i, top filter) were resuspended in the original volume in $20 \mathrm{mM}$ Tris, $\mathrm{pH} 7.4$, and $100 \mathrm{mM} \mathrm{NaCl}$, transferred into a new eppendorf tube and stored at $4{ }^{\circ} \mathrm{C}$. The final $\alpha$-syn oligomer concentration was determined by amino acid analysis (Functional Genomics Center, UZH/ETH, Zurich, Switzerland).

Expression and purification of tau. The longest tau isoform (tau441) was expressed in $E$. coli strain BL21. The purification protocol was adapted from Harbison et al. ${ }^{63}$ After induction with IPTG for $5 \mathrm{~h}$, cells were pelleted, broken by sonication in lysis buffer (3 M urea in $10 \mathrm{mM}$ MES, pH 6.5, $1 \mathrm{mM}$ DTT, $1 \mathrm{mM}$ EDTA and $1 \mathrm{mM}$ PMSF). After centrifugation at $150000 \times \mathrm{g}$ for $1 \mathrm{~h}$ at $4{ }^{\circ} \mathrm{C}, 1 \%(\mathrm{w} / \mathrm{V})$ of streptomycin sulfate was added to the supernatant, and the solution stirred for $90 \mathrm{~min}$ at $4^{\circ} \mathrm{C}$. After centrifugation for $1 \mathrm{~h}$ at $27000 \times \mathrm{g}$, the supernatant was dialyzed overnight in IEX buffer A (10 mM MES, pH 6.5, $20 \mathrm{mM} \mathrm{NaCl}, 1 \mathrm{mM}$ DTT and $1 \mathrm{mM}$ EDTA). The supernatant was filtered and loaded onto a cation-exchange column (monoS Fisher Scientific AG; IEX buffer A: $10 \mathrm{mM}$ MES, pH 6.5, $20 \mathrm{mM}$ $\mathrm{NaCl}, 1 \mathrm{mM}$ DTT and $1 \mathrm{mM}$ EDTA; IEX buffer B: $10 \mathrm{mM}$ MES, pH 6.5, $1 \mathrm{M} \mathrm{NaCl}$, $1 \mathrm{mM}$ DTT and $1 \mathrm{mM}$ EDTA). Fractions containing the proteins were dialyzed overnight in acetic buffer (5\% acetic acid in water) and loaded on a reverse-phase HPLC C4 column (PROTO 300 C4 $10 \mu \mathrm{m}$, Higgins Analytical, Mountain View, CA, USA; buffer A: 0.1\% TFA in water, buffer B: 0.1\% TFA in acetonitrile)

Preparation and characterization of tau fibrils. Tau fibrils were formed by incubating $300 \mu \mathrm{l}$ of monomeric tau at $300 \mu \mathrm{M}$ in the presence of $50 \mu \mathrm{M}$ heparin sodium salt (Applichem $\mathrm{GmbH}$, Darmstadt, Germany) under constant orbital agitation (1000 r.p.m., Peqlab) at $37^{\circ} \mathrm{C}$ for $72 \mathrm{~h}$, in $10 \mathrm{mM} \mathrm{HEPES}, 100 \mathrm{mM} \mathrm{NaCl}$ and $2.5 \mathrm{mM}$ DTT, pH 7.4. The fibrils were mechanically broken down into small fragments by 10 min bath sonication (ultrasonic cleaner, VWR, Dietikon, Switzerland). Sonicated tau fibrils were aliquoted, snap frozen in liquid nitrogen and stored at $-80^{\circ} \mathrm{C}$

Neuroblastoma cell culture. M17 neuroblastoma cell lines were maintained in $50 \% \mathrm{~F}-12,50 \%$ MEM supplemented in $10 \% \mathrm{FCS}, 100 \mu \mathrm{g} / \mu \mathrm{l}$ streptomycin and $100 \mathrm{U} / \mathrm{ml}$ penicillin (Life Technologies).

Primary culture of hippocampal neurons. Primary hippocampal neurons were prepared from P0 pups from mice (C57BL/6JRccHsd, Harlan) as previously described. ${ }^{64}$ Briefly, the cerebral hippocampi were isolated stereoscopically and dissociated by trituration in medium containing papain $(20 \mathrm{U} / \mathrm{ml}$, Sigma-Aldrich). Hippocampal neurons were cultured in Neurobasal medium containing B27 supplement, L-glutamine and penicillin/streptomycin (Life Technologies). The neurons were seeded in 96-well plates or onto coverslips (CS; VWR) previously coated with poly-L-lysine $0.1 \% \mathrm{w} / \mathrm{v}$ in water (Sigma-Aldrich) at a density of $150000 \mathrm{cells} / \mathrm{ml}$. After 7 days, the cells were treated with cytosine $\beta$-D-arabinofuranoside (Sigma-Aldrich) to a final concentration of $2.3 \mu \mathrm{M}$ to inhibit glial cell division. The neurons were used after 14 days in culture (2 weeks old). 
Hippocampal slice cultures. Transverse hippocampal organotypic slice cultures ( $400 \mu \mathrm{m}$ thick) from 6- to 7-day-old rats were prepared as described by Stoppini et $a l^{65}$. Slices were cultured on small membrane confetti on top of a Millipore insert to facilitate transfer of slice cultures to recording conditions $(6-8 \mathrm{~mm}$ in diameter; Millipore). Slice cultures were maintained in a $\mathrm{CO}_{2}(5 \%)$ incubator at $37^{\circ} \mathrm{C}$ for 2 days, then at $33^{\circ} \mathrm{C}$ with medium changed every $3-4$ days.

Immunocytochemistry. M17 cells or hippocampal primary neurons were seeded onto coverslips coated with poly--Llysine (Life Technologies) and treated with extracellular $\alpha$-syn monomers and/or fibrils for the indicated time point. For live imaging, hippocampal primary neurons were infected with DsRed viral particles (gift from Professor Patrick Aebischer, Lausanne, Switzerland) 1 week before incubation with $\alpha$-syn species. After the treatment, cells were washed 3 times with phosphatebuffered saline (PBS) and then fixed in 4\% paraformaldehyde (PFA) for 20 min at $4{ }^{\circ} \mathrm{C}$. After blocking with $3 \%$ bovine serum albumin (BSA) in $0.1 \%$ Triton X-100 PBS (PBS-T) for 30 min at RT, mammalian cells or hippocampal primary neurons were incubated with primary antibodies (rabbit anti- $\alpha$-syn and/or mouse anti-MAP2 and/or mouse $\beta$-catenin) for $2 \mathrm{~h}$ at RT. The cells were rinsed 5 times in PBS-T and subsequently incubated with the secondary anti-mouse Alexa ${ }^{405}$, anti-mouse Alexa ${ }^{488}$ or anti-rabbit Alexa ${ }^{568}$ at a dilution of $1: 800$ in PBS-T. The cells were washed 5 times in PBS-T and incubated for $30 \mathrm{~min}$ at RT in DAPI at $2 \mu \mathrm{g} / \mathrm{ml}$ (Life Technologies), before mounting in polyvinyl alcohol mounting medium with DABCO (Sigma-Aldrich). The cells were then examined with confocal laser-scanning microscope (LSM 700, Carl Zeiss Microscopy, Oberkochen, Germany) with a 20x or a $63 \times$ objective and analyzed using Zen software.

\section{Quantification of cell death by dye exclusion method in mammalian cell lines, in hippocampal slices culture and in hippocampal primary neurons \\ M17 neuroblastoma cell lines: M17 cell lines were plated in 24-well plate and treated for $24 \mathrm{~h}$ after plating with extracellular monomeric $\alpha$-syn, fibrillar $\alpha$-syn, oligomeric $\alpha$-syn or a mixture of monomeric and fibrillar $\alpha$-syn or a mixture of monomeric and oligomeric $\alpha$-syn. After 2 or 4 days of treatment, cell death was quantified by the vital dye exclusion method using $\mathrm{Pl}$, a membrane-impermeant dye that enters only in cells with damaged plasma membranes. Briefly, the supernatant and the adherent cells were harvested and collected in FACS tubes. Cells were then centrifuged for $5 \mathrm{~min}$ at $500 \times \mathrm{g}$. The pelleted cells were resuspended in PBS. PI was added to the cells at a final concentration of $2 \mu \mathrm{g} / \mathrm{ml}$ (Millipore). Cells were then analyzed by flow cytometry using Accuri C6 (BD Biosciences). PI emission was collected in FI2 channel and FlowJo software (Treestar, Ashland, OR, USA) was used for subsequent analysis.}

Hippocampal slice cultures: Hippocampal slice cultures were treated at day in vitro (DIV) 13-14 with extracellular monomeric $\alpha$-syn, fibrillar $\alpha$-syn or a mixture of monomeric and fibrillar $\alpha$-syn. For each of these conditions, other slice cultures form the same batch were treated with Tris buffer $(50 \mathrm{mM}$ Tris, pH 7.5, $150 \mathrm{mM}$ $\mathrm{NaCl}$ ) and used as control. After $24 \mathrm{~h}$, cell death was measured by quantification of PI-positive cells in the CA1 region. PI $(5 \mu \mathrm{g} / \mathrm{ml})$ was added to the culture medium and incubated for $20 \mathrm{~min}$ at $33^{\circ} \mathrm{C}$. After washing with culture medium, images of CA1 area were acquired under a $10 \times$ objective mounted on an epifluoresence Axioskop2 microscope equipped with an AxioCam connected to Axiovision software (Carl Zeiss Microscopy). Quantification of PI-positive cells in CA1 pyramidal layer was done with a custom-made Matlab program (Natick, MA, USA).

Hippocampal primary neurons: Hippocampal primary neurons were plated in 96-well plate and treated with extracellular monomeric $\alpha$-syn, fibrillar $\alpha$-syn, oligomeric $\alpha$-syn or a mixture of monomeric and fibrillar $\alpha$-syn or a mixture of monomeric and oligomeric $\alpha$-syn. After 3 or 6 days of treatment, cell death was quantified by the vital dye exclusion method using Sytox Green (SG, Life Technology), a membrane impermeant dye that enters only in cells with damaged plasma membranes. Briefly, the cells were washed 3 times with PBS before being incubated with SG at a final concentration of $330 \mathrm{nM}$. After $15 \mathrm{~min}$ of incubation, cells were washed twice with PBS and fluorescence was quantified using Tecan infinite M200 Pro plate reader (Tecan, Männedorf, Switzerland) with respective excitation and emission wavelength of 487 and $519 \mathrm{~nm}$.

TUNEL method in neuroblastoma cell lines and in hippocampal primary neurons. DNA fragmentation was detected using the TUNEL method as described by Gavrieli et al. ${ }^{66} \mathrm{M} 17$ and SH-SY5Y cells or hippocampal primary neurons were seeded on coverslips and treated with $\alpha$-syn monomers and/or fibrils for the indicated time. Then, the cells were washed 3 times with PBS to remove unattached recombinant $\alpha$-syn and fixed in $4 \%$ PFA for 15 min at $4{ }^{\circ} \mathrm{C}$. Cells were permeabilized in a solution composed of $0.1 \%$ Triton X-100 in $0.1 \%$ citrate buffer, $\mathrm{pH} \mathrm{6.0,} \mathrm{and} \mathrm{then} \mathrm{washed} \mathrm{in} \mathrm{PBS} \mathrm{buffer} \mathrm{before} \mathrm{incubation} \mathrm{with} \mathrm{terminal}$ deoxynucleotide transferase (In Situ Cell Death Detection kit; Roche) for $1 \mathrm{~h}$ at $37^{\circ} \mathrm{C}$ in a solution containing TMR red dUTP.

The nucleus was counterstained with SG at $0.5 \mu \mathrm{M}$ (Life Technologies) by $15 \mathrm{~min}$ of incubation in PBS. For the hippocampal primary neurons, the neurons were also specifically stained for NeuN, a nuclear neuronal marker (see Immunocytochemistry section). The cells were washed five times in PBS before mounting in polyvinyl alcohol (PVA) mounting medium with the anti-fading DABCO reagent (SigmaAldrich). The cells plated on CS were then examined with a microscope (Axioplan, Carl Zeiss Microscopy) with a $20 \times$ objective and analyzed using ImageJ (US National Institutes of Health, Bethesda, MD, USA).

Quantification of active caspases 3, 8 and 9 in neuroblastoma cell lines and in hippocampal primary neurons. CaspaTag fluorescein caspase 3,8 or 9 activity kit (Millipore) allows the detection of active effector caspase (caspase 3 ) or initiator caspases (caspases 8 or 9 ) in living cells. These kits used specific fluorochrome peptide inhibitors of caspases (FLICA) respectively: FAM-DEVD-fmk for caspase 3, FAM-LETD-FMK for caspase 8 and FAM-LEHD- fmk for caspase 9 . These probes passively enter the cells and bind irreversibly to the active caspases.

At 4 days after treatment with $\alpha$-syn monomers and/or $\alpha$-syn fibrils in the presence or not of the caspases inhibitors (Z-VAD-fmk (general caspase inhibitor), IETD-fmk (caspase 8 inhibitor) and LEHD-fmk (caspase 9 inhibitor)), M17 and SH-S5Y5 cells were harvested and incubated for $1 \mathrm{~h}$ at $37^{\circ} \mathrm{C}$ with FAM-DEVDFMK (caspase 3), FAM-LETD-fmk (caspase 8) or FAM-LEHD-fmk (caspase 9) and with $\mathrm{PI}$ in accordance with the supplier's instructions. Fluorescein emission was analyzed by flow cytometry (Accuri C6 (BD Biosciences)) in Fl1 channel and $\mathrm{PI}$ emission was collected in $\mathrm{Fl} 3$ channel. FlowJo was used for subsequent analysis.

For hippocampal primary neurons, cells were washed 3 times with PBS and incubated for $30 \mathrm{~min}$ at $37^{\circ} \mathrm{C}$ with FAM-DEVD-FMK (caspase 3), FAM-LETD-fmk (caspase 8) or FAM-LEHD-fmk (caspase 9) or with SG in accordance with the supplier's instructions. Fluorescein emission was quantified using Tecan infinite M200 Pro plate reader (Tecan) with respective excitation and emission wavelength of 487 and $519 \mathrm{~nm}$.

Proteostat staining. Hippocampal primary neurons or M17 were plated on CS and treated with extracellular monomeric $\alpha$-syn, fibrillar $\alpha$-syn, oligomeric $\alpha$-syn or a mixture of monomeric and fibrillar $\alpha$-syn or a mixture of monomeric and oligomeric $\alpha$-syn. After $\alpha$-syn treatment ( 2 days of treatment for the M17 and 3 days of treatment for the primary neurons), cells were washed 3 times with PBS to remove unattached recombinant $\alpha$-syn from the cells and fixed in 4\% PFA. Proteostat staining (Enzo Life Sciences) was performed to visualize $\alpha$-syn aggregates formed at the cell plasma membrane. After permeabilization on ice with $0.5 \%$ Triton X-100, cells were incubated for 30 min with the proteostat aggregation detection dye. Proteostat dye binds specifically to the cross- $\beta$ spine quaternary structure of amyloid-like protein aggregates. ${ }^{39-41}$ ICC was then performed to detect $\alpha$-syn (see Immunocytochemistry section) and the cells plated on CS were then examined with confocal laser-scanning microscope (LSM 700, Carl Zeiss Microscopy) with a $63 \times$ objective and analyzed using Zen software (Carl Zeiss Microscopy).

Cell lysis and WB. Proteins samples (after purification) or cells were resuspended in $2 \times$ LB and boiled for $10 \mathrm{~min}$. Proteins were then separated on a $15 \%$ SDS-PAGE gel and transferred onto nitrocellulose membrane (Fisher Scientific, Lucens, Switzerland) with a semi-dry system (Bio-Rad, Crissier, Switzerland). Membranes were probed overnight at $4{ }^{\circ} \mathrm{C}$ with the primary antibody of interest after $30 \mathrm{~min}$ of blocking in Odyssey blocking buffer (Li-Cor Biosciences, Bad Homburg, Germany) diluted 1:3 in PBS (Sigma-Aldrich). After four washes with PBS and $0.01 \%(\mathrm{v} / \mathrm{v})$ Tween-20 (PBS-T, Sigma-Aldrich), membranes were incubated for $1 \mathrm{~h}$ with secondary antibodies (goat or rabbit Alexa Fluor ${ }^{680} \operatorname{lgG}$ ) protected from light at RT. Immunoblots were finally washed 4 times with PBS-T and scanned using a Li-COR scanner (Li-Cor Biosciences) at a wavelength of 700 or $800 \mathrm{~nm}$. 
EM analysis of hippocampal neurons. Mouse primary hippocampal neurons were grown on fluorodishes with alphanumeric searching grids etched to the bottom glass (IBIDI, Vitaris, Baar, Switzerland; small square size of $50 \times 50 \mu \mathrm{m}$ ) and treated with labeled $\alpha$-syn ${ }^{A 594}$ PFFs alone $(2 \mu \mathrm{M})$ or with a mixture composed of $\alpha$-syn monomers $(18 \mu \mathrm{M})$ and $\alpha$-syn ${ }^{A 594}$ PFFs $(2 \mu \mathrm{M})$. At the indicated time point, cells were washed 3 times with PBS and fixed with $4 \%$ PFA for $10 \mathrm{~min}$ Nucleus of the primary neurons was counterstained with DAPI (Life Technologies). Neurons with labeled $\alpha$-syn ${ }^{A 594}$ at their surface were selected with fluorescence confocal microscope (LSM700, Carl Zeiss Microscopy) for ultrastructural analysis. The precise position of the selected neuron was recorded using the coordinates of the grid. The fluorodishes were then incubated with $2.5 \%$ glutaraldehyde and $2.0 \%$ paraformaldehyde in $0.1 \mathrm{M}$ phosphate buffer (PB) at $\mathrm{pH} 7.4$ for $2 \mathrm{~h}$. After extensive washing (5 times for $5 \mathrm{~min}$ ) with $0.1 \mathrm{M}$ cacodylate buffer at $\mathrm{pH} 7.4$, cells were post fixed with $1 \%$ osmium tetroxide in $0.1 \mathrm{M}$ cacodylate buffer at $\mathrm{pH} 7.4$ for $1 \mathrm{~h}$ and washed with double-distilled water twice for $5 \mathrm{~min}$ each wash and en block contrasted with $1 \%$ uranyl acetate in double-distilled water for $1 \mathrm{~h}$. After washing with double-distilled water, neurons were dehydrated in graded alcohol series $(2 \times 50 \%, 1 \times 70 \%, 1 \times 90 \%, 1 \times 95 \%$ and $2 \times$ absolute ethanol) for 3 min each wash. Dehydrated cells were infiltrated with Durcupan resin diluted with absolute ethano at $1: 2$ for $30 \mathrm{~min}$, at $1: 1$ for $30 \mathrm{~min}$ and $2: 1$ for $30 \mathrm{~min}$ and twice with pure Durcupan (Electron Microscopy Sciences, Hatfield, PA, USA) for 30 min each. After $2 \mathrm{~h}$ of incubation in fresh Durcupan resin, the fluorodishes were transferred into $65^{\circ} \mathrm{C}$ oven to polymerize and cure the resin overnight. The bottom glass CS of the fluorodishes were removed from the hard resin by immersing the fluorodishes into $60^{\circ} \mathrm{C}$ hot water followed by liquid nitrogen until the CS parted. At this stage the alphanumeric searching grids were also imprinted to the polymerized resin. To easily cut out the selected cells from resin disk and to facilitate the trimming process, a laser dissecting microscope (Leica LDM, Leica Microsystems, Vienna, Austria) was used to mark the position of selected neurons on the surface of the resin block. The selected neuron was cut off from the disk using single edge razor-blade, glued to dummy resin block with superglue and the cutting face trimmed using a ultramicrotome (Leica Ultracut UCT, Leica Microsystems) and a glass knife. Ultrathin sections $(50-60 \mathrm{~nm})$ were cut with a diamond knife (DiATOME, Biel, Switzerland) and collected onto $2 \mathrm{~mm}$ single-slot copper grids coated with formvar plastic support film. Sections were contrasted with uranyl acetate and lead citrate and examined using Tecnai Spirit TEM (FEI) operating at $80 \mathrm{kV}$ of acceleration voltage and equipped with bottom mounted $4 \mathrm{k} \times 4 \mathrm{k}$ Eagle CCD camera controlled by TIA acquisition software (FEI).

Relative quantification of WB and statistical analysis. The level of monomeric or fibrillar $\alpha$-syn were estimated by measuring the WB band intensity using ImageJ software and normalized to the relative protein levels of actin. The experiments were independently repeated three times.

The statistical analyses were performed using ANOVA test followed by Tukey-Kramer post-hoc test. The data were regarded as statistically significant at $P<0.05$

\section{Conflict of Interest}

The authors declare no conflict of interest.

Acknowledgements. This work was supported by funding from the EPFL, ERC starting grant 587137 (to HAL and A-LM-M), Era.net 591123 (to FV), Swiss National Science Foundation 513354 (to HAL) and 310030B-144080 (to MDR and DM), CHD A-7627 (to BM) and ACl 520030 (to NA-B). We especially thank Professor Dominique Muller who died on 29 April 2015. He will be deeply missed by the scientific community. We thank Dr. Carole Desobry and Dr. John Warner for their help in preparing fluorescently labeled $\alpha$-syn, Nathalie Jordan for preparing the neuronal primary culture and Celine Vocat for expressing and purifying some of the $\alpha$-syn recombinant protein used in this study. We thank Mohamed Bilal Fares for his careful and insightful reading of our manuscript. We also thank Professor Darren Moore for providing the M17 cells and Professor Patrick Aebischer (EPFL, Switzerland) for providing DsRed viral particles and SH-S5Y5 cell lines.

1. Goedert M, Spillantini MG, Del Tredici K, Braak H. 100 years of Lewy pathology. Nat Rev Neurol 2013; 9: 13-24

2. Lashuel HA, Overk CR, Oueslati A, Masliah E. The many faces of alpha-synuclein: from structure and toxicity to therapeutic target. Nat Rev Neurosci 2013; 14: 38-48.
3. Li JY, Englund E, Holton JL, Soulet D, Hagell P, Lees AJ et al. Lewy bodies in grafted neurons in subjects with Parkinson's disease suggest host-to-graft disease propagation. Nat Med 2008; 14: 501-503.

4. Kordower JH, Chu Y, Hauser RA, Olanow CW, Freeman TB. Transplanted dopaminergic neurons develop PD pathologic changes: a second case report. Mov Disord 2008; 23: 2303-2306.

5. Mollenhauer B, Trautmann E, Taylor P, Manninger P, Sixel-Doring F, Ebentheuer $\mathrm{J}$ et al. Total CSF alpha-synuclein is lower in de novo Parkinson patients than in healthy subjects. Neurosci Lett 2013; 532: 44-48.

6. Lee HJ, Patel S, Lee SJ. Intravesicular localization and exocytosis of alpha-synuclein and its aggregates. J Neurosci 2005; 25: 6016-6024.

7. Marques O, Outeiro TF. Alpha-synuclein: from secretion to dysfunction and death. Cell Death Dis 2012; 3: e350.

8. Lee HJ, Bae EJ, Lee SJ. Extracellular alpha-synuclein-a novel and crucial factor in Lewy body diseases. Nat Rev Neurol 2014; 10: 92-98

9. Emmanouilidou E, Melachroinou K, Roumeliotis T, Garbis SD, Ntzouni M, Margaritis LH et al. Cell-produced alpha-synuclein is secreted in a calcium-dependent manner by exosomes and impacts neuronal survival. J Neurosci 2010; 30: 6838-6851.

10. Alvarez-Erviti L, Seow Y, Schapira AH, Gardiner C, Sargent IL, Wood MJ et al. Lysosomal dysfunction increases exosome-mediated alpha-synuclein release and transmission. Neurobiol Dis 2011; 42: 360-367.

11. Winner B, Jappelli $R$, Maji SK, Desplats PA, Boyer $L$, Aigner $S$ et al. In vivo demonstration that alpha-synuclein oligomers are toxic. Proc Natl Acad Sci USA 2011; 108: 4194-4199.

12. Desplats $P$, Lee HJ, Bae EJ, Patrick C, Rockenstein E, Crews L et al. Inclusion formation and neuronal cell death through neuron-to-neuron transmission of alpha-synuclein. Proc Natl Acad Sci USA 2009; 106: 13010-13015.

13. Luk KC, Kehm VM, Zhang B, O'Brien P, Trojanowski JQ, Lee VM. Intracerebral inoculation of pathological alpha-synuclein initiates a rapidly progressive neurodegenerative alphasynucleinopathy in mice. J Exp Med 2012; 209: 975-986.

14. Luk KC, Kehm V, Carroll J, Zhang B, O'Brien P, Trojanowski JQ et al. Pathological alphasynuclein transmission initiates Parkinson-like neurodegeneration in nontransgenic mice. Science (New York, NY) 2012; 338: 949-953.

15. Recasens A, Dehay B, Bove J, Carballo-Carbajal I, Dovero S, Perez-Villalba A et al. Lewy body extracts from Parkinson disease brains trigger alpha-synuclein pathology and neurodegeneration in mice and monkeys. Ann Neurol 2014; 75: 351-362.

16. Hansen C, Angot E, Bergstrom AL, Steiner JA, Pieri L, Paul G et al. alpha-Synuclein propagates from mouse brain to grafted dopaminergic neurons and seeds aggregation in cultured human cells. J Clin Invest 2011; 121: 715-725.

17. Volpicelli-Daley LA, Luk KC, Patel TP, Tanik SA, Riddle DM, Stieber A et al. Exogenous alpha-synuclein fibrils induce Lewy body pathology leading to synaptic dysfunction and neuron death. Neuron 2011; 72: 57-71.

18. Luk KC, Song C, O'Brien P, Stieber A, Branch JR, Brunden KR et al. Exogenous alphasynuclein fibrils seed the formation of Lewy body-like intracellular inclusions in cultured cells. Proc Natl Acad Sci USA 2009; 106: 20051-20056.

19. Alvarez-Erviti L, Couch Y, Richardson J, Cooper JM, Wood MJ. Alpha-synuclein release by neurons activates the inflammatory response in a microglial cell line. Neurosci Res 2011; 69: 337-342.

20. Zhang W, Wang T, Pei Z, Miller DS, Wu X, Block ML et al. Aggregated alpha-synuclein activates microglia: a process leading to disease progression in Parkinson's disease. FASEB J 2005; 19: 533-542.

21. Lee HJ, Suk JE, Patrick C, Bae EJ, Cho JH, Rho S et al. Direct transfer of alpha-synuclein from neuron to astroglia causes inflammatory responses in synucleinopathies. J Biol Chem 2010; 285: 9262-9272.

22. Di Giovanni S, Eleuteri S, Paleologou KE, Yin G, Zweckstetter M, Carrupt PA et al. Entacapone and tolcapone, two catechol O-methyltransferase inhibitors, block fibril formation of alpha-synuclein and beta-amyloid and protect against amyloid-induced toxicity. J Biol Chem 2010; 285: 14941-14954.

23. El-Agnaf OM, Jakes R, Curran MD, Middleton D, Ingenito R, Bianchi E et al. Aggregates from mutant and wild-type alpha-synuclein proteins and NAC peptide induce apoptotic cell death in human neuroblastoma cells by formation of beta-sheet and amyloid-like filaments. FEBS Lett 1998; 440: 71-75.

24. Wright JA, Wang $X$, Brown DR. Unique copper-induced oligomers mediate alpha-synuclein toxicity. FASEB J 2009; 23: 2384-2393.

25. Lee EN, Cho HJ, Lee CH, Lee D, Chung KC, Paik SR. Phthalocyanine tetrasulfonates affect the amyloid formation and cytotoxicity of alpha-synuclein. Biochemistry 2004; 43: 3704-3715.

26. Jan A, Hartley DM, Lashuel HA. Preparation and characterization of toxic Abeta aggregates for structural and functional studies in Alzheimer's disease research. Nat Protoc 2010; 5: 1186-1209.

27. Jan A, Gokce O, Luthi-Carter R, Lashuel HA. The ratio of monomeric to aggregated forms of Abeta40 and Abeta42 is an important determinant of amyloid-beta aggregation, fibrillogenesis, and toxicity. J Biol Chem 2008; 283: 28176-28189.

28. Fauvet B, Mbefo MK, Fares MB, Desobry C, Michael S, Ardah MT et al. alphaSynuclein in central nervous system and from erythrocytes, mammalian cells, and Escherichia coli exists predominantly as disordered monomer. J Biol Chem 2012; 287: 15345-15364. 
29. Yamakawa K, Izumi Y, Takeuchi H, Yamamoto N, Kume T, Akaike A et al. Dopamine facilitates alpha-synuclein oligomerization in human neuroblastoma SH-SY5Y cells. Biochem Biophys Res Commun 2010; 391: 129-134.

30. Fagerqvist T, Nasstrom T, Ihse E, Lindstrom V, Sahlin C, Tucker SM et al. Off-pathway alphasynuclein oligomers seem to alter alpha-synuclein turnover in a cell model but lack seeding capability in vivo. Amyloid 2013; 20: 233-244.

31. Lee HJ, Baek SM, Ho DH, Suk JE, Cho ED, Lee SJ. Dopamine promotes formation and secretion of non-fibrillar alpha-synuclein oligomers. Exp Mol Med 2011; 43: 216-222.

32. Luk KC, Lee VM. Modeling Lewy pathology propagation in Parkinson's disease. Parkinsonism Relat Disord 2014; 20: S85-S87.

33. Jan A, Adolfsson O, Allaman I, Buccarello AL, Magistretti PJ, Pfeifer A et al. Abeta42 neurotoxicity is mediated by ongoing nucleated polymerization process rather than by discrete Abeta42 species. J Biol Chem 2011; 286: 8585-8596.

34. Wogulis M, Wright S, Cunningham D, Chilcote T, Powell K, Rydel RE. Nucleation-dependent polymerization is an essential component of amyloid-mediated neuronal cell death. J Neurosci 2005; 25: 1071-1080.

35. Biere AL, Wood SJ, Wypych J, Steavenson S, Jiang Y, Anafi D et al. Parkinson's diseaseassociated alpha-synuclein is more fibrillogenic than beta- and gamma-synuclein and cannot cross-seed its homologs. J Biol Chem 2000; 275: 34574-34579.

36. Tsigelny IF, Bar-On P, Sharikov Y, Crews L, Hashimoto M, Miller MA et al. Dynamics of alpha-synuclein aggregation and inhibition of pore-like oligomer development by betasynuclein. FEBS J 2007; 274: 1862-1877.

37. Hashimoto M, Rockenstein E, Mante M, Mallory M, Masliah E. beta-Synuclein inhibits alphasynuclein aggregation: a possible role as an anti-parkinsonian factor. Neuron 2001; 32: 213-223.

38. Giasson BI, Forman MS, Higuchi M, Golbe LI, Graves CL, Kotzbauer PT et al. Initiation and synergistic fibrillization of tau and alpha-synuclein. Science (New York, NY) 2003; 300: 636-640.

39. Cook NP, Kilpatrick K, Segatori L, Marti AA. Detection of alpha-synuclein amyloidogenic aggregates in vitro and in cells using light-switching dipyridophenazine ruthenium(II) complexes. J Am Chem Soc 2012; 134: 20776-20782.

40. Kilpatrick K, Novoa JA, Hancock T, Guerriero CJ, Wipf P, Brodsky JL et al. Chemical induction of Hsp70 reduces alpha-synuclein aggregation in neuroglioma cells. ACS Chem Biol 2013; 8: 1460-1468.

41. Shen D, Coleman J, Chan E, Nicholson TP, Dai L, Sheppard PW et al. Novel cell- and tissuebased assays for detecting misfolded and aggregated protein accumulation within aggresomes and inclusion bodies. Cell Biochem Biophys 2011; 60: 173-185.

42. Galluzzi L, Vitale I, Abrams JM, Alnemri ES, Baehrecke EH, Blagosklonny MV et al. Molecular definitions of cell death subroutines: recommendations of the Nomenclature Committee on Cell Death 2012. Cell Death Differ 2012; 19: 107-120.

43. Forloni G, Bertani I, Calella AM, Thaler F, Invernizzi R. Alpha-synuclein and Parkinson's disease: selective neurodegenerative effect of alpha-synuclein fragment on dopaminergic neurons in vitro and in vivo. Ann Neurol 2000; 47: 632-640.

44. Lee HJ, Choi C, Lee SJ. Membrane-bound alpha-synuclein has a high aggregation propensity and the ability to seed the aggregation of the cytosolic form. J Biol Chem 2002; 277: 671-678.

45. Hertel C, Hauser N, Schubenel R, Seilheimer B, Kemp JA. Beta-amyloid-induced cell toxicity: enhancement of 3-(4,5-dimethylthiazol-2-yl)-2,5-diphenyltetrazolium bromidedependent cell death. J Neurochem 1996; 67: 272-276.

46. Soriano FX, Galbete JL, Forloni G. Effect of beta-amyloid on endothelial cells: lack of direct toxicity, enhancement of MTT-induced cell death and intracellular accumulation. Neurochem Int 2003; 43: 251-261.

47. Kane MD, Schwarz RD, St Pierre L, Watson MD, Emmerling MR, Boxer PA et al. Inhibitors of V-type ATPases, bafilomycin A1 and concanamycin A, protect against beta-amyloidmediated effects on 3-(4,5-dimethylthiazol-2-yl)-2,5-diphenyltetrazolium bromide (MTT) reduction. J Neurochem 1999; 72: 1939-1947.

48. Brandner S, Isenmann S, Raeber A, Fischer M, Sailer A, Kobayashi $Y$ et al. Normal host prion protein necessary for scrapie-induced neurotoxicity. Nature 1996; 379: 339-343.
49. Holmes BB, DeVos SL, Kfoury N, Li M, Jacks R, Yanamandra K et al. Heparan sulfate proteoglycans mediate internalization and propagation of specific proteopathic seeds. Proc Natl Acad Sci USA 2013; 110: E3138-E3147.

50. Liu IH, Uversky VN, Munishkina LA, Fink AL, Halfter W, Cole GJ. Agrin binds alpha-synuclein and modulates alpha-synuclein fibrillation. Glycobiology 2005; 15 : 1320-1331.

51. Cohlberg JA, Li J, Uversky VN, Fink AL. Heparin and other glycosaminoglycans stimulate the formation of amyloid fibrils from alpha-synuclein in vitro. Biochemistry 2002; 41: 1502-1511.

52. Reynolds NP, Soragni A, Rabe M, Verdes D, Liverani E, Handschin S et al. Mechanism of membrane interaction and disruption by alpha-synuclein. J Am Chem Soc 2011; 133: 19366-19375.

53. Galvagnion C, Buell AK, Meisl G, Michaels TC, Vendruscolo M, Knowles TP et al. Lipid vesicles trigger alpha-synuclein aggregation by stimulating primary nucleation. Nat Chem Biol 2015; 11: 229-234.

54. Buell AK, Galvagnion C, Gaspar R, Sparr E, Vendruscolo M, Knowles TP et al. Solution conditions determine the relative importance of nucleation and growth processes in alpha-synuclein aggregation. Proc Natl Acad Sci USA 2014; 111: 7671-7676.

55. Jeong JS, Ansaloni A, Mezzenga R, Lashuel HA, Dietler G. Novel mechanistic insight into the molecular basis of amyloid polymorphism and secondary nucleation during amyloid formation. J Mol Biol 2013; 425: 1765-1781.

56. Cohen SI, Linse S, Luheshi LM, Hellstrand E, White DA, Rajah L et al. Proliferation of amyloid-beta42 aggregates occurs through a secondary nucleation mechanism. Proc Natl Acad Sci USA 2013; 110: 9758-9763.

57. Chaudhary H, Stefanovic AN, Subramaniam V, Claessens MM. Membrane interactions and fibrillization of alpha-synuclein play an essential role in membrane disruption. FEBS Lett 2014; 588: 4457-4463

58. Pacheco CR, Morales CN, Ramirez AE, Munoz FJ, Gallegos SS, Caviedes PA et al. Extracellular alpha-synuclein alters synaptic transmission in brain neurons by perforating the neuronal plasma membrane. J Neurochem 2015; 132: 731-741.

59. Choi WS, Eom DS, Han BS, Kim WK, Han BH, Choi EJ et al. Phosphorylation of p38 MAPK induced by oxidative stress is linked to activation of both caspase-8- and -9-mediated apoptotic pathways in dopaminergic neurons. J Biol Chem 2004; 279: 20451-20460.

60. Viswanath $\mathrm{V}, \mathrm{Wu} \mathrm{Y}$, Boonplueang $\mathrm{R}$, Chen $\mathrm{S}$, Stevenson FF, Yantiri $\mathrm{F}$ et al. Caspase-9 activation results in downstream caspase-8 activation and bid cleavage in 1-methyl-4-phenyl-1,2,3,6-tetrahydropyridine-induced Parkinson's disease. J Neurosci2001; 21: 9519-9528.

61. Ouberai MM, Wang J, Swann MJ, Galvagnion C, Guilliams T, Dobson CM et al. alphaSynuclein senses lipid packing defects and induces lateral expansion of lipids leading to membrane remodeling. J Biol Chem 2013; 288: 20883-20895.

62. Lashuel HA, Hartley D, Petre BM, Walz T, Lansbury Jr PT. Neurodegenerative disease: amyloid pores from pathogenic mutations. Nature 2002; 418: 291.

63. Harbison NW, Bhattacharya S, Eliezer D. Assigning backbone NMR resonances for full length tau isoforms: efficient compromise between manual assignments and reduced dimensionality. PLoS One 2012; 7: e34679.

64. Steiner P, Sarria JC, Glauser L, Magnin S, Catsicas S, Hirling H. Modulation of receptor cycling by neuron-enriched endosomal protein of $21 \mathrm{kD}$. J Cell Biol 2002; 157 : 1197-1209.

65. Stoppini L, Buchs PA, Muller D. A simple method for organotypic cultures of nervous tissue. J Neurosci Methods 1991; 37: 173-182.

66. Gavrieli Y, Sherman Y, Ben-Sasson SA. Identification of programmed cell death in situ via specific labeling of nuclear DNA fragmentation. J Cell Biol 1992; 119: 493-501.

67. Cappai R, Leck SL, Tew DJ, Williamson NA, Smith DP, Galatis D et al. Dopamine promotes alpha-synuclein aggregation into SDS-resistant soluble oligomers via a distinct folding pathway. FASEB J 2005; 19: 1377-1379.

\section{Supplementary Information accompanies this paper on Cell Death and Differentiation website (http://www.nature.com/cdd)}

